\title{
Espécies de Cladonia P. Browne (Cladoniaceae, Ascomycota) do Supergrupo Cladonia em restingas e costões rochosos dos Estados do Paraná e de Santa Catarina, Brasil
}

\author{
Emerson Luiz Gumboski ${ }^{1,2}$ e Sionara Eliasaro ${ }^{1}$
}

Recebido: 17.04.2012; aceito: 20.06.2012

\begin{abstract}
Species of Cladonia P. Browne (Cladoniaceae, Ascomycota) of Supergroup Cladonia from restinga vegetation and rocky shores in the States of Paraná and Santa Catarina, Brazil). A total of 14 species of Cladonia were found, of which four are new records: Cladonia latiloba and C. ochracea are new records to Paraná; C. merochlorophaea and C. polyscypha are new records to Santa Catarina. Most of the species were found both in restinga vegetation and on rocky shores. Cladonia flagellaris and C. litoralis were found only on rocky shores while C. merochlorophaea, C. polyscypha, C. signata and C. solida only in restinga vegetation. Identification key, descriptions, comments and illustrations are presented.
\end{abstract}

Key words: Coast, lichenized fungi, taxonomy

RESUMO - (Espécies de Cladonia P. Browne (Cladoniaceae, Ascomycota) do Supergrupo Cladonia em restingas e costões rochosos dos Estados do Paraná e de Santa Catarina, Brasil). Foram registradas 14 espécies de Cladonia, das quais quatro são novas ocorrências: Cladonia latiloba e C. ochracea para o Paraná; C. merochlorophaea e C. polyscypha para Santa Catarina. A maioria das espécies foi encontrada tanto em restingas quanto em costões rochosos. Cladonia flagellaris e C. litoralis foram encontradas apenas em costões enquanto que C. merochlorophaea, C. polyscypha, C. signata e C. solida apenas em restingas. São apresentadas chave de identificação, descrições, comentários e ilustrações.

Palavras-chave: Fungos liquenizados, litoral, taxonomia

\section{Introdução}

O Supergrupo Cladonia do gênero Cladonia P. Browne foi proposto por Stenroos et al. (2002a) que incluíram neste as espécies tratadas por Ahti (2000) nas seções Ascyphiferae, Helopodium e Cladonia. Esse Supergrupo foi definido por características moleculares do DNA, sendo que todas as características morfológicas e químicas comumente utilizadas para separar as seções se revelaram homoplasias e definiam somente pequenos grupos de espécies ou até mesmo uma única espécie (Stenroos et al. 2002a). Desse modo, as espécies desse Supergrupo são bastante diversificadas morfologicamente. $\mathrm{O}$ talo primário pode ser evanescente e desaparecer por completo, como nas espécies previamente incluídas na Seção Ascyphiferae, ou persistente e conspícuo (Seção Helopodium), representando a parte dominante do talo. Os talos secundários (podécios), que podem ser corticados ou ecorticados, variam de simples a muito ramificados, e apresentam desde ápices agudos até a formação de grandes cifas. A maioria das espécies apresenta as axilas fechadas, isto é, sem perfurações. Os discos himeniais e os picnídios são marrons (Swinscow \& Krog 1988, Archer 1992, Ahti 2000). A química, entretanto, é mais homogênea, sendo que a maioria das espécies produz ácido fumarprotocetrárico (Burgaz \& Ahti 2009).

Das 51 espécies de Cladonia registradas para os Estados do Paraná e de Santa Catarina (Ahti \& Marcelli 1995, Ahti 2000, Gumboski 2011, Gumboski \& Eliasaro 2011a, b) 28 pertencem ao Supergrupo Cladonia. No entanto, essas referências são baseadas principalmente em exemplares coletados em planaltos, na Serra Geral e Serra do Mar (Müller 1891a, b, Marcelli 1992, Ahti 2000).

1. Universidade Federal do Paraná, Departamento de Botânica, Laboratório de Liquenologia, Caixa Postal 19031, 81531-970 Curitiba, PR, Brasil

2. Autor para correspondência: emerson_gumboski@yahoo.com.br 
Para as restingas dos Estados do Paraná e de Santa Catarina, Ahti (2000) registrou doze espécies de Cladonia, das quais apenas cinco pertencem ao Supergrupo Cladonia: C. ceratophylla (Sw.) Spreng., C. furfuracea Vain., C. latiloba Ahti \& Marcelli, C. subradiata (Vain.) Sandst. e C. subsquamosa Kremp. Gumboski \& Eliasaro (2011a) recentemente descreveram a única espécie desse Supergrupo conhecida para costões rochosos desses Estados.

\section{Material e métodos}

As coletas foram realizadas em restingas e costões rochosos selecionados em 11 cidades ao longo do litoral do Paraná e Santa Catarina e seguiram a metodologia descrita em Brodo et al. (2001). Em laboratório, os materiais foram secos em temperatura ambiente, herborizados e depois incorporados ao Herbário UPCB da Universidade Federal do Paraná. As análises morfológicas foram realizadas sob microscópio estereoscópico $(20-50 \times)$ e para as análises anatômicas, cortes feitos à mão livre foram observados sob microscópio fotônico (400-1000×), ambos com ocular dotada de retículo graduado. Para a identificação de metabólitos secundários de importância taxonômica foram utilizados testes de coloração (K, C e KC) de córtex e medula segundo Taylor $(1967,1968)$, observação do talo sob lâmpada UV (Taylor 1967, 1968) e cromatografia em camada delgada (CCD) seguindo Culberson \& Ammann (1979) e Elix \& Ernst-Russell (1993).

\section{Resultados e Discussão}

Foram encontradas 14 espécies pertencentes ao Supergrupo Cladonia. Cladonia latiloba Ahti \& Marcelli e $C$. ochracea L. Scriba são novas citações para o Estado do Paraná; enquanto que C. merochlorophaea Asahina e C. polyscypha Ahti \& L. Xavier Filho são novas citações para o Estado de Santa Catarina.
Dentre as 12 espécies registradas em Santa Catarina, nove foram coletadas em costões rochosos e 11 em restingas, enquanto que das 10 registradas no Paraná, sete foram coletadas em costões e oito em restingas (tabela 1). Cladonia ceratophylla, C. furfuracea, C. latiloba, C. ochracea e C. subsquamosa ocorreram tanto em restingas quanto em costões rochosos e em ambos os Estados. Todas essas aparentemente possuem uma ampla plasticidade quanto à colonização de substratos, o que concorda com as diferentes citações feitas por Vainio (1887, 1894), Marcelli (1990), Fleig et al. (1995) e Ahti (2000).

Seis espécies apresentaram distribuição bem restrita. Duas ocorreram somente em costões rochosos: Cladonia flagellaris Ahti \& Marcelli e C. litoralis Gumboski \& Eliasaro; e quatro somente em restingas: C. merochlorophaea, C. polyscypha, C. signata (Eschw.) Vain e $C$. solida Vain. Tais espécies geralmente foram encontradas em aglomerados bem pequenos (até $0,06 \mathrm{~m}^{2}$ ) e em determinados locais, por exemplo, C. merochlorophaea e C. solida somente foram encontradas na restinga do Parque Estadual do Acaraí/SC, C. polyscypha apenas na restinga de Itapoá/ $\mathrm{SC}$ e C. signata somente na restinga de Guaraqueçaba/ PR (dois espécimes) e Matinhos/PR (um espécime). Destas, C. solida foi a única que formava um aglomerado expressivo, com aproximadamente $4 \mathrm{~m}^{2}$.

Em praticamente todas as espécies foi detectada a produção de ácido fumarprotocetrárico como composto secundário principal, dessas, apenas Cladonia ceratophylla também produzia atranorina. Nas espécies $C$. merochlorophaea e C. latiloba não foi detectado a produção de ácido fumarprotocetrárico, sendo que em $C$. merochlorophaea foi detectado ácido merocloroféico, enquanto em $C$. latiloba foi detectado a produção de atranorina, ácido estíctico e ácido norestíctico. Entretanto, é importante ressaltar que Ahti (2000) citou que as duas últimas espécies mencionadas possuem quimiotipos que produzem ácido fumarprotocetrárico.

Chave artificial para as espécies de Cladonia pertencentes ao Supergrupo Cladonia encontradas em restingas e costões rochosos no sul do Brasil

1. Esquâmulas primárias como parte dominante do talo, geralmente bem desenvolvidas ou, quando diminutas sem podécios

2. Esquâmulas primárias com até $0,5 \mathrm{~mm}$ de comprimento C. ramulosa

2. Esquâmulas primárias maiores que $1,0 \mathrm{~mm}$ de comprimento

3. Esquâmulas com rizinas marginais C. ceratophylla

3. Esquâmulas sem rizinas marginais 
4. Talo primário com aspecto pulviniforme, podécio principalmente ecorticado, coberto por grânulos C. litoralis

4. Talo primário sem aspecto pulviniforme, podécio corticado, sem grânulos

5. Esquâmulas primárias laciniadas, podécios clavados, $\mathrm{K}+$ amarelo forte (atranorina) C. latiloba

5. Esquâmulas primárias lobadas, arredondadas, podécios subulados, $\mathrm{K}-$ ou $\mathrm{K}+$ amarelo sujo (ácido fumarprotocetrárico) C. pityrophylla

1. Esquâmulas primárias ausentes ou, quando presentes, geralmente diminutas, podécio sempre presente, a parte mais desenvolvida do talo

6. Podécio e/ou axilas acifosas

7. Podécio oco, muito ramificado C. signata

7. Podécio sólido, pouco a moderadamente ramificado C. solida

6. Podécio cifoso, ao menos com ápices ou axilas estreitamente cifosas

8. Podécio verticilado C. flagellaris

8. Podécio não verticilado, raramente com uma projeção cifosa central

9. Podécios exclusivamente cifosos, cifas com até 4,5 $\mathrm{mm}$ de diâmetro

10. Podécio corticado-areolado, sem sorédios 10. Podécio ecorticado, com sorédios C. merochlorophaea

9. Podécios não exclusivamente cifosos, alguns subulados ou capitados, cifas apicais ou axilares estreitas, com até $2,0 \mathrm{~mm}$ de diâmetro

11. Base suave a distintamente melanótica C. polyscypha

11. Base não melanótica

12. Podécio corticado, pelo menos na metade inferior

13. Superfície do podécio rugosa a lisa, porção superior escabrosa, com grânulos, filídios, esquisídios e esquâmulas C. ochracea

13. Superfície verrucosa, sem filídios e esquisídios, apenas grânulos e esquâmulas presentes C. ramulosa

12. Podécio ecorticado, às vezes com discreto anel corticado somente na base

14. Superfície do podécio sorediada C. subradiata 14. Superfície do podécio sem sorédios C. furfuracea

Cladonia ceratophylla (Sw.) Spreng., Syst. Veg. 4: $271.1827 \equiv$ Lichen ceratophyllus Sw., Prodr. Nov. Plant. Spec. India Occ.: 147. 1788. Tipo: JAMAICA (lectótipo S, designado por Ahti (1993); isolectótipos BM, H-ACH 1576, UPS).

Figura 1

Talo primário: persistente, geralmente a parte mais conspícua, composto por esquâmulas, $0,4-1,6 \mathrm{~cm}$ de comprimento, 3,0-8,0 mm de largura, principalmente lobadas a raramente laciniadas, sem sorédios, margem lisa a irregularmente crenada, involuta, rizinas presentes, geralmente abundantes, brancas a negras, até $1,8 \mathrm{~mm}$ de comprimento; superfície superior corticada, esverdeada a verde amarelada, pouco lustrosa, lisa, sem pruína; superfície inferior ecorticada, aracnoide, branca; córtex 30-50 $\mu \mathrm{m}$ de espessura, medula 70-190 $\mu \mathrm{m}$ de espessura; picnídios ausentes. Talo secundário: $0,8-2,0(-3,0) \mathrm{cm}$ de altura, 0,3-0,8 mm de espessura, esbranquiçado, simples a pouco ramificado, com até quatro ramos laterais, acifoso, ápice subulado, base não melanótica, perfurações ausentes; superfície corticada somente na base, levemente velosa a rugulosa, sorediada ao longo do podécio, grânulos presentes, às vezes apresentando grânulos isidióides, esquâmulas às vezes presentes, podendo se desenvolver muito e a partir das mesmas, novos podécios se originam; córtex 20-40 $\mu \mathrm{m}$ de espessura, medula 100-200 $\mu \mathrm{m}$ de espessura, estereoma hialino, 50-110 $\mu \mathrm{m}$ de espessura, irregularmente entremeado com a medula, canal central suavemente papilado, 200-700 $\mu \mathrm{m}$ de diâmetro; discos himeniais ausentes; picnídios raros, no ápice dos ramos, ovoides, amarronzados a enegrecidos, imaturos, mucilagem ausente, conídios ausentes.

Química: Testes de coloração: $\mathrm{K}+$ amarelo forte, C-, KC-, UV-. CCD: Ácido fumarprotocetrárico, atranorina e uma substância não identificada com Rf C aproximado de 20.

Cladonia ceratophylla é caracterizada pelas esquâmulas primárias conspícuas, alongadas, com 
rizinas marginais, podécios laminais, ecorticados e granulosos (Vainio 1887, Fleig et al. 1995). Na área de estudo foi a única espécie a apresentar rizinas marginais nas esquâmulas primárias, tornando-a facilmente identificável mesmo em campo.

Cladonia pityrophylla Nyl. é similar por apresentar as esquâmulas primárias bem desenvolvidas e por ambas produzirem ácido fumarprotocetrárico. Contudo, C. ceratophylla possui esquâmulas primárias alongadas, com rizinas marginais e podécios ecorticados, enquanto que $C$. pityrophylla possui esquâmulas primárias arredondadas, sem rizinas marginais e podécios principalmente corticados. Além disso, C. ceratophylla frequentemente produz atranorina ao passo que $C$. pityrophylla produz principalmente ácido fumarprotocetrárico e nunca atranorina.

Cladonia latiloba também apresenta esquâmulas primárias bem desenvolvidas e alongadas, porém, C. ceratophylla possui rizinas marginais, podécios ecorticados e subulados, enquanto que a C. latiloba não têm rizinas marginais e os podécios são corticados e clavados.

Distribuição: Possui uma ampla ocorrência mundial, sendo encontrada na Oceania, Ásia, África, América do Norte, América Central (Vainio 1887) e América do Sul: na Argentina, Bolívia, Colômbia, Equador, Guiana, Paraguai, Peru, Suriname, Trinidad e Tobago, Uruguai, Venezuela (Vainio 1887, Grassi 1950 apud Calvelo \& Liberatore 2002, Sipman 1990, Sipman \& Aptroot 1992, Ahti 2000) e no Brasil, para os Estados da BA, ES, MG, PR, RJ, RS, SC e SP (Krempelhuber 1876, Müller 1881, Vainio 1887, Osorio \& Fleig 1988a, Ahti 2000, Gumboski \& Eliasaro 2011b).

Habitat: Segundo Ahti (2000), Cladonia ceratophylla ocorre desde o nível do mar até $3900 \mathrm{~m}$ de altitude e de acordo com Vainio (1887), Fleig et al. (1995) e Ahti (2000) a colonização de substratos pela espécie é bastante variável. Na área de estudo desenvolve-se em áreas bem iluminadas ou pouco sombreadas, sendo comumente encontrada nas restingas e mais raramente em costões rochosos. Embora seja principalmente terrícola (arenícola), também pode ocorrer sobre córtices de árvores, diretamente sobre rochas e serapilheira, às vezes entremeadas com podécios de Cladonia subsquamosa, C. subradiata e/ou C. didyma (Fée) Vain.

Espécimes selecionados examinados: BRASIL. PARANÁ: Guaraqueçaba, Ilha das Peças, restinga, 26-XII-2003, C.G. Donha 1351 (UPCB); Paranaguá,

Tabela 1. Ocorrência das espécies de Cladonia (Supergrupo Cladonia) nos ambientes estudados baseada na quantidade de materiais coletados e observações de campo, Estados do Paraná e de Santa Catarina, Brasil.

Table 1. Occurrence of species of Cladonia (Supergrupo Cladonia) in the studied environments based on the amount of materials collected and field observations, Paraná and Santa Catarina States, Brazil.

\begin{tabular}{lllll}
\hline & \multicolumn{3}{c}{ Santa Catarina } & Paraná \\
\cline { 2 - 5 } Espécies & Costão rochoso & Restinga & Costão rochoso & Restinga \\
\hline C. ceratophylla & Frequente & Frequente & Frequente & Frequente \\
C. flagellaris & - & - & Rara & - \\
C. furfuracea & Frequente & Frequente & Frequente & Frequente \\
C. latiloba & Rara & Abundante & Rara & Frequente \\
C. litoralis & Rara & - & - & - \\
C. merochlorophaea & - & Rara & - & - \\
C. ochracea & Frequente & Abundante & Frequente & Abundante \\
C. pityrophylla & Rara & Frequente & Rara & - \\
C. polyscypha & - & Rara & - & - \\
C. ramulosa & Frequente & Frequente & - & Frequente \\
C. signata & - & - & - & Rara \\
C. solida & - & Rara & - & - \\
C. subradiata & Frequente & Frequente & - & Frequente \\
C. subsquamosa & Frequente & Abundante & Frequente & Abundante \\
\hline
\end{tabular}


Parque Estadual da Ilha do Mel, restinga, 2531'S, $48^{\circ} 18^{\prime} \mathrm{O}, 27-\mathrm{VIII}-2009$, E. Gumboski \& S. Eliasaro 1571 (UPCB), costão rochoso na Praia de Fora, 27-VIII-2009, 2532'S, 48 $17^{\circ} \mathrm{O}$, E. Gumboski \& S. Eliasaro 1622 (UPCB); Pontal do Paraná, Pontal do Sul, restinga arbórea, 28-II-2008, M. Dal-Forno 547, 548 (UPCB). Santa Catarina: São Francisco do Sul, Morro João Dias, costão rochoso, $26^{\circ} 10^{\prime} \mathrm{S}, 48^{\circ} 31^{\prime} \mathrm{O}$, 5-III-2009, E. Gumboski 668 (UPCB), Parque Estadual do Acaraí, restinga, $26^{\circ} 15^{\prime} \mathrm{S}, 48^{\circ} 31^{\prime} \mathrm{O}, 17-\mathrm{III}-2009$, E. Gumboski 730, 820, 911 (UPCB), 26 $23^{\prime} \mathrm{S}, 48^{\circ} 33^{\prime} \mathrm{O}$, 18-IV-2009, E. Gumboski 1329, 1334 (UPCB); Balneário Camboriú, Praia Taquarinhos, 28-X-2004, M. Schatzmann s.n. (UPCB 55781); Bombinhas, Praia de Mariscal, costão rochoso, $26^{\circ} 13^{\prime} \mathrm{S}, 48^{\circ} 29^{\prime} \mathrm{O}$, 19-II-2010, E. Gumboski \& F. Beilke 1719, 1743 (UPCB); Laguna, Praia da Galheta, costão rochoso, $28^{\circ} 33^{\prime} \mathrm{S}, 48^{\circ} 47^{\prime} \mathrm{O}, 19-\mathrm{II}-2010$, E. Gumboski \& F. Beilke 1775, 1776 (UPCB), área ao lado da rodovia BR-101, restinga arbustiva, $28^{\circ} 24^{\prime} \mathrm{S}, 48^{\circ} 47^{\prime} \mathrm{O}$, 9-III-2009, E. Gumboski 774 (UPCB).

Cladonia flagellaris Ahti \& Marcelli, Biblioth. Lichenol. 58: 18. 1995. Tipo: BRASIL. São PAULO: Peruíbe, Reserva Ecológica Juréia-Itatins, 1993, Marcelli \& Yano 23721 (holótipo SP; isótipo H). Figura 2

Talo primário: ausente. Talo secundário: 1,5-6,0 cm de altura, 0,3-1,0 $\mathrm{mm}$ de espessura, acinzentado a verde esbranquiçado, simples a dicotomicamente ramificado, cifoso, em arranjo verticilado, com 3-6 cifas sobrepostas, 4,0-10,0 mm de diâmetro, margens profundamente laciniadas, lacínias dicotômicas, 1,2-3,3 mm de comprimento, sólidas a ocas, raramente com rizinas negras terminais, até $1,0 \mathrm{~mm}$ de comprimento, base necrótica melanótica, perfurações ausentes, porém, fissuras vão se tornando presentes na parte superior das cifas à medida que as mesmas vão se desenvolvendo; superfície corticada areolada, aracnoide, sem sorédios e grânulos, esquâmulas mais comuns em talos mais jovens, levemente alongadas, distribuição aleatória, suavemente pruinosa na metade superior; córtex fragmentado na metade inferior e areolado-aracnoide na metade superior, (0-)20-40 $\mu \mathrm{m}$ de espessura, medula entremeando-se em partes com o estereoma, 40-100 $\mu \mathrm{m}$ de espessura, estereoma hialino a levemente amarelado na metade superior e fortemente melanótico na metade inferior, $50-120 \mu \mathrm{m}$ de espessura, canal central papilado, 800-1050 $\mu \mathrm{m}$ de diâmetro; discos himeniais ausentes; picnídios no ápice ou próximos a base das lacínias marginais, globosos, marrons enegrecidos, mucilagem hialina, conídios filiformes suavemente curvados a quase retos, $6-8 \times 1 \mu \mathrm{m}$.

Química: Testes de coloração: K-, C-, KC-, UV-. CCD: Ácido fumarprotocetrárico e uma substância não identificada com Rf C aproximado de 28.

De acordo com Ahti \& Marcelli (1995), Cladonia flagellaris é caracterizada pelo podécio verticilado, corticado, contendo de três a cinco cifas sobrepostas, com margens laceradas e base necrótica distintamente melanótica.

Esta espécie é bastante similar a Cladonia imperialis Ahti \& Marcelli por apresentar podécio verticilado, corticado, com cifas laceradas, base necrótica melanótica e por produzir ácido fumarprotocetrárico (Ahti 2000). Porém, C. flagellaris apresenta podécios com 1,5 a 6,0 cm de altura e de três a seis cifas sobrepostas, enquanto $C$. imperialis apresenta podécios com 10,0 a $25,0 \mathrm{~cm}$ de altura e em geral de 12 a 15 cifas sobrepostas, raramente chegando a 26 (Ahti \& Marcelli 1995).

Pode ser diferenciada das demais espécies que possuem podécios verticilados e que apresentam cifas laceradas (e.g. Cladonia crinita (Delise ex Pers.) Ahti e C. verticillaris (Raddi) Fr.) por possuir a base necrótica distintamente melanótica, ao passo que as outras não apresentam base melanótica (Ahti 2000).

A forma e as dimensões dos conídios estão sendo descritas pela primeira vez para esta espécie.

Distribuição: Conhecida somente para o Brasil e mencionada para os Estados de MG, PR, RJ e SP (Ahti \& Marcelli 1995, Ahti 2000).

Habitat: Cladonia flagellaris ocorre, segundo Ahti (2000), desde o nível do mar até 2.300 metros de altitude sobre afloramentos rochosos em áreas pouco expostas. Rara na área de estudo, somente foi encontrada em costão rochoso na Ilha do Mel, Paraná, em local parcialmente sombreado, diretamente sobre as rochas ou sobre briófitas saxícolas. Cresce isolada de outras espécies de Cladonia.

Espécimes examinados: BRASIL. PARANÁ: Paranaguá, Parque Estadual da Ilha do Mel, costão rochoso próximo a fortaleza, $25^{\circ} 30^{\prime} \mathrm{S}, 48^{\circ} 18^{\prime} \mathrm{O}, 27-\mathrm{VIII}-2009$, E. Gumboski \& S. Eliasaro 1623, 1624, 1625, 1626 (UPCB). 

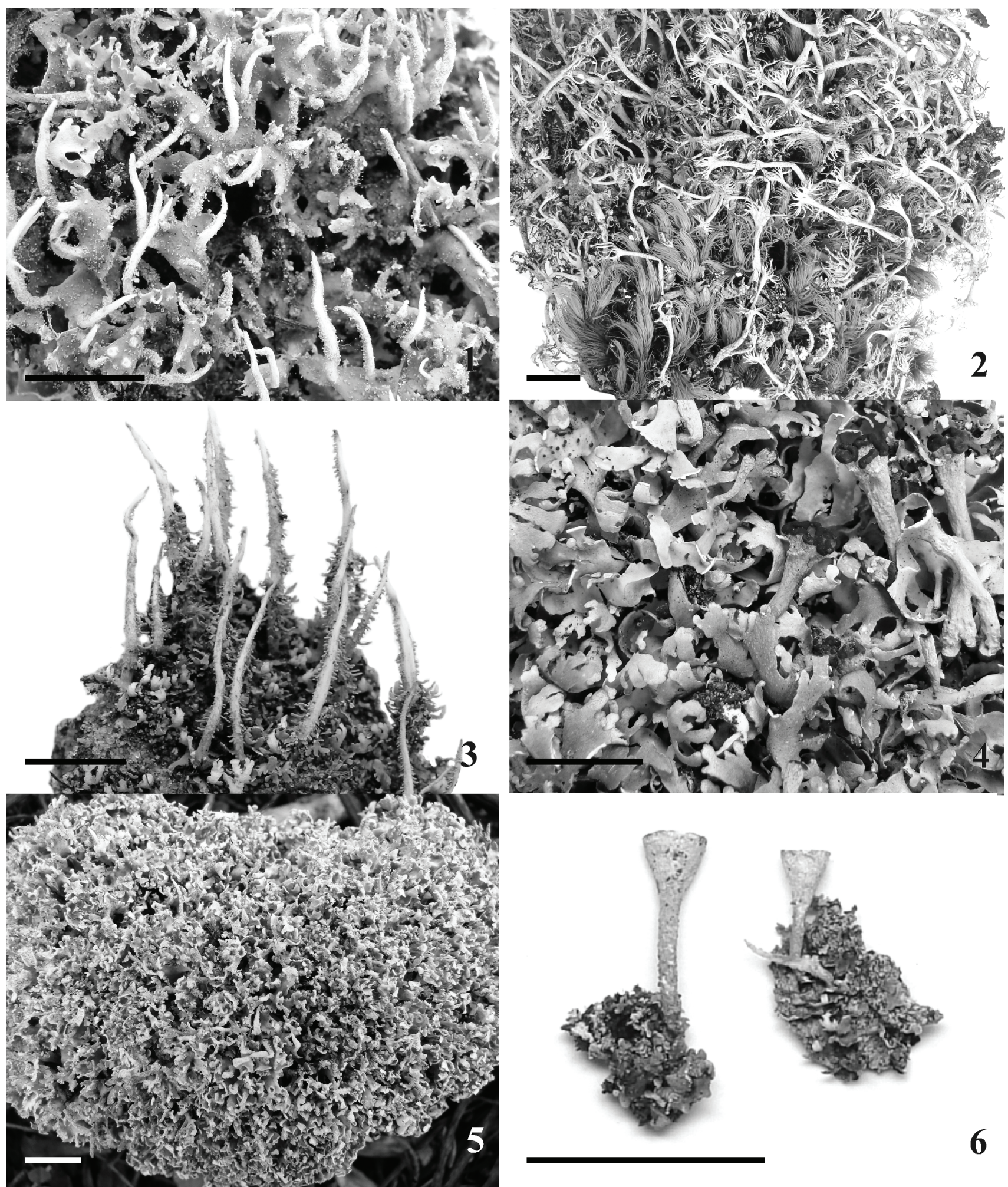

Figuras 1-6: 1. Cladonia ceratophylla (E. Gumboski \& S. Eliasaro 1622). 2. C. flagellaris (E. Gumboski \& S. Eliasaro 1624). 3. C. furfuracea (E. Gumboski 1332). 4. C. latiloba (R.A. Reis 13). 5. C. litoralis (E. Gumboski \& F. Beilke 1771). 6. C. merochlorophaea (E. Gumboski $752 b)$. Barras de escala $=1 \mathrm{~cm}$.

Figures 1-6: 1. Cladonia ceratophylla (E. Gumboski \& S. Eliasaro 1622). 2. C. flagellaris (E. Gumboski \& S. Eliasaro 1624). 3. C. furfuracea (E. Gumboski 1332). 4. C. latiloba (R.A. Reis 13). 5. C. litoralis (E. Gumboski \& F. Beilke 1771). 6. C. merochlorophaea (E. Gumboski $752 b)$. Scale bars $=1 \mathrm{~cm}$. 
Cladonia furfuracea Vain., Acta Soc. Fauna Fl. Fenn. 10:375. 1894. Tipo: BRASIL. Minas Gerais: Caraça, 1885, Vainio s.n. (lectótipo TUR-V 19992, designado por Ahti (1993); isolectótipos FH, G, H, M, TUR-V, UPS, US).

Figura 3

Talo primário: evanescente, inconspícuo, composto de esquâmulas, 0,5-2,0 $\mathrm{mm}$ de comprimento, 0,2-0,6 $\mathrm{mm}$ de largura, laciniadas a lobuladas, ocre, pouco recortadas, sem sorédios, margem lisa, sem rizinas; superfície superior corticada, lisa, lustrosa, comumente com pequenos pontos pruinosos; superfície inferior ecorticada, aracnoide, branca; córtex 10-30 $\mu \mathrm{m}$ de espessura, medula 25-40 $\mu \mathrm{m}$ de espessura; picnídios ausentes. Talo secundário: 0,5-1,5(-2,5) cm de altura, 0,4-1,2 $\mathrm{mm}$ de espessura, cifoso, simples a pouco ramificado, com ramificações originando-se principalmente das margens das cifas, às vezes laterais, ápices cifosos a subulados, às vezes capitados, cifas 0,3-1,6 mm de diâmetro, com uma a três ramificações marginais, ecorticada, granulosa internamente, base não melanótica, perfurações ausentes; superfície do podécio ecorticada, levemente aracnoide, geralmente com o estereoma exposto, escurecido a amarronzado, sem sorédios, pouco granuloso principalmente próximo ao ápice e dentro das cifas, bastante coberto por esquâmulas, laciniadas a isidióides, raramente recortadas, até $0,7 \mathrm{~mm}$ de comprimento; medula 10-18 $\mu \mathrm{m}$ de espessura, estereoma 70-100 $\mu \mathrm{m}$ de espessura, canal central ranhurado, 400-900 $\mu \mathrm{m}$ de diâmetro; discos himeniais marrons enegrecidos, apicais, até $1,2 \mathrm{~mm}$ de diâmetro, ascósporos oblongos, 11-17 × 3-5 $\mu \mathrm{m}$; picnídios presentes na margem das cifas, negros, piriformes, conídios filiformes suavemente curvados, 6-9 $\times 1 \mu \mathrm{m}$.

Química: Testes de coloração: K-, C-, KC-, UV-. CCD: Ácido fumarprotocetrárico.

De acordo com as descrições de Vainio (1894) e Fleig et al. (1995), Cladonia furfuracea é caracterizada pelo podécio simples a pouco ramificado, totalmente ecorticado, estreito cifoso, sem sorédios, estereoma geralmente exposto, coberto por esquâmulas e pela presença de grânulos verruculosos. Bem como pela produção de ácido fumarprotocetrárico.

Cladonia furfuraceoides Ahti \& Sipman é uma espécie bastante próxima de $C$. furfuracea, ambas possuem podécios estreitamente cifosos, ecorticados, com grânulos e esquâmulas, discos himeniais marrons e produzem ácido fumarprotocetrárico
(Stenroos et al. 2002a). No entanto, C. furfuracea não possui a base do podécio melanótica e apresenta esquâmulas isidióides, enquanto que $C$. furfuraceoides possui a base do podécio distintamente melanótica e não apresenta esquâmulas isidióides, somente esquâmulas lobadas ao longo do podécio. Além disso, C. furfuraceoides ocorre da Guiana a Colômbia (norte da América do Sul) enquanto C. furfuracea é uma espécie brasileira que ocorre estritamente na região costeira (Stenroos et al. 2002a).

Quando o podécio não apresenta disco himenial, Cladonia furfuracea pode ser confundida com C. didyma (Fée) Vain. devido ao fato de ambas apresentarem podécios geralmente simples, com esquâmulas e estereoma exposto (Gumboski 2011). No entanto, C. furfuracea possui o podécio geralmente cifoso e produz ácido fumarprotocetrárico, enquanto que $C$. didyma apresenta o podécio subulado, acifoso e produz ácido barbático e/ou ácido didímico (Fleig et al. 1995, Ahti 2000).

Distribuição: De acordo com Ahti \& Sipman em Stenroos et al. (2002a), os registros de Cladonia furfuracea para a Guiana (Sipman \& Aptroot 1992, Ahti 2000), Venezuela, Colômbia e para os Estados brasileiros do Amazonas e Roraima (Ahti 2000), provavelmente referem-se a Cladonia furfuraceoides. O que limita a distribuição de $C$. furfuracea apenas para a costa do Brasil, sendo citada para os Estados da BA, ES, MG, PB, PE, PR, RJ, RS, SC, SE e SP (Vainio 1894, Marcelli 1990, Marcelli 1992, Ahti et al. 1993, Fleig et al. 1995, Ahti 2000).

Habitat: $\mathrm{Na}$ área de estudo foi encontrada tanto em restingas quanto em costões rochosos, porém nem sempre formando colônias conspícuas. Geralmente ocorre em locais bem iluminados e de forma isolada, embora também possa ocorrer junto com exemplares de Cladonia subsquamosa, C. subradiata, C. didyma e C. ochracea. Coloniza principalmente solos arenosos, embora raramente tenha sido encontrada sobre serapilheira, bases de árvores mortas ou entre musgos.

Espécimes selecionados examinadas: BRASIL. PARANÁ: Guaraqueçaba, Ilha das Peças, restinga, $25^{\circ} 28^{\prime} \mathrm{S}, 48^{\circ} 17^{\prime} \mathrm{O}, 20-\mathrm{III}-2010$, E. Gumboski \& F. Beilke 1809 (UPCB); Paranaguá, Parque Estadual da Ilha do Mel, restinga, $25^{\circ} 31^{\prime} \mathrm{S}, 48^{\circ} 18^{\prime} \mathrm{O}$, 28-VIII-2009, E. Gumboski \& S. Eliasaro 1610, 1619 (UPCB), costão rochoso na Praia de Fora, $25^{\circ} 32^{\prime} \mathrm{S}, 48^{\circ} 17^{\prime} \mathrm{O}$, 28-VIII-2009, E. Gumboski \& S. Eliasaro 1643 (UPCB); Matinhos, Ilha das Tartarugas, costão 
rochoso, 2551'S, 48 32'O, 21-III-2010, E. Gumboski \& F. Beilke 1832, 1835, 1839 (UPCB). SANTA Catarina: São Francisco do Sul, Morro da Enseada, costão rochoso, $26^{\circ} 13^{\prime} \mathrm{S}, 48^{\circ} 29^{\prime} \mathrm{O}, 19-\mathrm{VI}-2008$, E. Gumboski 531 (UPCB), Parque Estadual do Acaraí, restinga, $26^{\circ} 15^{\prime} \mathrm{S}, 48^{\circ} 31^{\prime} \mathrm{O}, 17-\mathrm{III}-2009$, E. Gumboski $806,809,812,901,915$ (UPCB); Bombinhas, Praia de Mariscal, costão rochoso ao norte da praia, $26^{\circ} 13^{\prime} \mathrm{S}$, 48²9'O, 19-II-2010, E. Gumboski \& F. Beilke 1733 (UPCB).

Cladonia latiloba Ahti \& Marcelli, Fl. Neotrop., Monogr. 78: 249. 2000. Tipo: BRASIL. SÃo PAULO: Iguape, Barra do Ribeira, 1989, Marcelli 6921 (holótipo SP; isótipo H).

Figura 4

Talo primário: persistente, muito desenvolvido, composto por esquâmulas com até $3,5 \mathrm{~cm}$ de comprimento, 0,5-3,0(-4,4) $\mathrm{mm}$ de largura, laciniadas, profundamente recortadas, sem sorédios, margens geralmente lisas, sem rizinas; superfície superior corticada, lisa, lustrosa, esverdeada, sem pruína; superfície inferior ecorticada, aracnoide, branca a oliva, escurecida principalmente em áreas voltadas para cima e expostas a luminosidade, o que ocorre com esquâmulas enroladas; picnídios laminais, marrom claro a negros, piriformes, mucilagem hialina, conídios filiformes levemente curvados, 7,5-10,0 × 1,0 $\mu \mathrm{m}$. Talo secundário: até $1,3 \mathrm{~cm}$ de altura, $0,2-2,3 \mathrm{~mm}$ de espessura, esverdeado, simples, às vezes com poucas ramificações apicais, clavado, acifoso, às vezes rompendo-se longitudinalmente deixando o estereoma exposto, perfurações ausentes; superfície do podécio corticada, verrucosa, frequentemente com fissuras longitudinais, sem sorédios e grânulos, às vezes apresenta esquâmulas principalmente próximas ao ápice, das quais, novos podécios podem ser formados, as esquâmulas podem atingir até $7,0 \mathrm{~mm}$ de comprimento; córtex 12,5-50,0 $\mu \mathrm{m}$ de espessura, medula 50-200 $\mu \mathrm{m}$ de espessura, estereoma hialino, 38-175 $\mu \mathrm{m}$ de espessura, canal central levemente estriado, às vezes fissurado, 150-1.900 $\mu \mathrm{m}$ de diâmetro; discos himeniais apicais, marrons, dispostos formando aglomerados, ascósporos oblongos, 9-11 × 3-4 $\mu \mathrm{m}$; picnídios laterais, enegrecidos, piriformes, mucilagem hialina, conídios filiformes levemente curvados, $7,5-10,0 \times 1,0 \mu \mathrm{m}$.

Química: Testes de coloração: $\mathrm{K}+$ amarelo forte, C-, KC-, UV-. CCD: Atranorina, ácido estíctico, ácido norestíctico e provavelmente ácido criptostíctico, além de um pigmento com $\mathrm{Rf} C$ aproximado de 90 .
Cladonia latiloba é caracterizada pelas esquâmulas primárias bem desenvolvidas, alongadas, bastante conspícuas, sem rizinas marginais, pelo podécio corticado, clavado e também pela produção de atranorina (Fleig et al. 1995, Ahti 2000).

De acordo com Ahti (2000), Cladonia latiloba é bastante similar a C. megaphylla Ahti \& Marcelli por ambas apresentarem esquâmulas primárias lobadas e alongadas. Contudo, C. latiloba apresenta podécio geralmente clavado, sem perfurações e atranorina como composto principal, enquanto que $C$. megaphylla apresenta podécio geralmente cilíndrico, geralmente com perfurações axilares e/ou laterais e produz ácido fumarprotocetrárico. Há também uma distribuição altitudinal entre as duas espécies, pois C. latiloba ocorre estritamente em planícies costeiras enquanto que C. megaphylla ocorre em áreas de planalto.

Cladonia latiloba é similar a C. subcariosa Nyl. por apresentar esquâmulas primárias alongadas, lobadas e por frequentemente produzir atranorina (Fleig et al. 1995 como C. polycarpoides Nyl.). Contudo, C. latiloba possui esquâmulas primárias com até 3,5 cm de comprimento e podécios clavados, enquanto que $C$. subcariosa, segundo descrição em Ahti (2000), possui esquâmulas primárias com o máximo de $1,0 \mathrm{~cm}$ de comprimento e podécios cilíndricos.

Cladonia ceratophylla pode lembrar C. latiloba por apresentar esquâmulas primárias conspícuas e por frequentemente produzir atranorina. Contudo, a abundância de rizinas nas esquâmulas primárias em $C$. ceratophylla juntamente com os podécios ecorticados a diferenciam claramente de C. latiloba, que não possui rizinas e apresenta podécios corticados.

As fissuras presentes na superfície interna do canal central de $C$. latiloba sugerem que os podécios se rompem a partir do estereoma, proporcionando, muitas vezes, um aspecto filopodial ao podécio.

Distribuição: Conhecida somente para o Brasil e para os Estados do RJ, RS, SC e SP (Fleig et al. 1995, Ahti 2000). Esta é a primeira citação para o Estado do Paraná.

Habitat: Cladonia latiloba é uma espécie exclusivamente costeira (Ahti 2000). Na área de estudo é comumente encontrada em restingas e ocasionalmente em costões rochosos, mas principalmente coloniza áreas bem iluminadas de restingas herbáceas. Sempre encontrada sobre solo arenoso, mesmo em costões localiza-se sobre camadas de sedimentos em concavidades das rochas ou próximas a vegetação, em áreas mais 
afastadas do spray salino. Às vezes entremeada com podécios de Cladonia ramulosa, C. furfuracea e C. didyma.

Espécimes selecionados examinados: BRASIL. Paraná: Paranaguá, Parque Estadual da Ilha do Mel, costão rochoso, $25^{\circ} 30^{\prime} \mathrm{S}, 48^{\circ} 18^{\prime} \mathrm{O}, 27-\mathrm{VIII}-2009$, E. Gumboski \& S. Eliasaro 1620 (UPCB), restinga, 5-II-2004, R.A. Reis 13 (UPCB); Pontal do Paraná, Balneário Ipanema, restinga, 8-V-2003, C.G. Donha 719 (UPCB). Santa Catarina: São Francisco do Sul, Morro João Dias, costão rochoso, $26^{\circ} 10^{\prime} \mathrm{S}$, 4831'O, 5-III-2009, E. Gumboski 667, 671, 676, 690 (UPCB), Parque Estadual do Acaraí, restinga, $26^{\circ} 15^{\prime} \mathrm{S}$, 4831'O, 17-III-2009, E. Gumboski 699a, 701, 714 (UPCB); Florianópolis, Costão do Santinho, costão rochoso, 27 26' S, 48 $22^{\prime} \mathrm{O}, 18-\mathrm{IV}-2010$, E. Gumboski, A.C.L. Gerlach \& L.F. Oliveira 1866, 1867 (UPCB); Laguna, Praia da Galheta, costão rochoso, $28^{\circ} 33^{\prime} \mathrm{S}$, 484', 19-II-2010, E. Gumboski \& F. Beilke 1782 (UPCB), área ao lado da rodovia BR-101, restinga, $28^{\circ} 24^{\prime}$ 'S, $48^{\circ} 47^{\prime}$ O, 9-III-2009, E. Gumboski 781 (UPCB).

Cladonia litoralis Gumboski \& Eliasaro, The Bryologist 114(4): 665.2011. Tipo: BRASIL. SANTA CATARINA: Bombinhas, Praia de Mariscal, 3 m alt., Fevereiro de 2010, E. Gumboski \& F. Beilke 1717 (holótipo UPCB; isótipos ICN, SP)

Figura 5

Talo primário: persistente, bem desenvolvido, apresenta aspecto pulviniforme, frouxo adnato, 4,0-7,5 cm de diâmetro, até $2,5 \mathrm{~cm}$ de altura, composto por esquâmulas, 1,0-7,0 mm de comprimento, 0,7-1,5 mm de largura, laciniadas, recortadas, suavemente convexas, sem sorédios, com margens involutas, lisas a irregularmente crenadas principalmente na porção apical, sem rizinas; superfície superior lisa, lustrosa, amarelado a verde amarelado, sem pruína; superfície inferior distintamente aracnoide, branca a amarronzada, às vezes com glomérulos algais presentes; córtex 20-35 $\mu \mathrm{m}$ de espessura, medula 120-223 $\mu \mathrm{m}$ de espessura; picnídios ausentes. Talo secundário: laminal a submarginal, abundante, às vezes numerosos na mesma esquâmula primária, 0,4-0,8 $\mathrm{mm}$ de altura, $0,3-0,5 \mathrm{~mm}$ de espessura, esbranquiçados, geralmente simples, raros com uma a duas ramificações, ápices subulados, acifosos, perfurações ausentes; superfície principalmente ecorticada, lisa a suavemente velosa, às vezes levemente rugosa, córtex presente na base, base constrita, poucas vezes o córtex se estende até a metade do podécio, sem sorédios, pouco a completamente coberto por grânulos e esquâmulas, grânulos globosos a isidióides, até $0,22 \mathrm{~mm}$ de comprimento, alguns grânulos apresentam o ápice amarronzado, esquâmulas lobadas a laciniadas, espessadas, geralmente não recortadas, até $1,5 \mathrm{~cm}$ de comprimento, às vezes dessas esquâmulas novos podécios são formados e a partir disso podem desenvolver-se ainda mais; córtex 0-30 $\mu \mathrm{m}$ de espessura, medula 50-130 $\mu \mathrm{m}$ de espessura, entremeando-se com o estereoma, estereoma hialino, 50-150 $\mu \mathrm{m}$ de espessura, canal central levemente ranhurado, 380-450 $\mu \mathrm{m}$ de diâmetro; discos himeniais ausentes; picnídios comuns, apicais a laterais, marrons, piriformes, até $0,2 \mathrm{~mm}$ de diâmetro, conídios levemente curvados, 7-10 × $1 \mu \mathrm{m}$.

Química: Testes de coloração: K+ amarelo suave, C-, KC-, UV-. CCD: Ácido fumarprotocetrárico.

Cladonia litoralis foi incluída no Supergrupo Cladonia por conter picnídios amarronzados a negros, axilas geralmente fechadas e por produzir ácido fumarprotocetrárico (Gumboski \& Eliasaro 2011a).

A espécie é a única neste Supergrupo com talo primário pulviniforme e podécios inconspícuos, acifosos, ecorticados, geralmente simples e com ápices subulados. O talo primário pulviniforme é uma característica muito marcante e que a diferencia da grande maioria das outras espécies.

Cladonia litoralis é semelhante a C. strepsilis (Ach.) Vain. e C. subcervicornis (Vain.) Kernst. por apresentar o talo primário pulviniforme. Entretanto, C. strepsilis produz estrepsilina (Brodo et al. 2001) e possui o podécio corticado ao passo que $C$. litoralis produz ácido fumarprotocetrárico e possui o podécio ecorticado. Cladonia subcervicornis, segundo Burgaz \& Ahti (2009), embora produza ácido fumarprotocetrárico, pode ser diferenciada pelo podécio cifoso e corticado.

De acordo com Gumboski \& Eliasaro (2011a), Cladonia litoralis pode ser confundida com uma forma esquamulosa de $C$. ochracea. Contudo, C. litoralis além do talo pulviniforme apresenta as margens e superfície inferior das esquâmulas primárias lisas, enquanto que em $C$. ochracea as esquâmulas primárias apresentam margens e superfície inferior granulosa, principalmente quando jovens. Outro ponto importante é que os podécios de $C$. litoralis não apresentam verrugas, esquisídios ou filídios como acontece em C. ochracea (Fleig et al. 1995). Os grânulos presentes nos podécios de $C$. litoralis são mais cilíndricos, com 
superfície lustrosa e córtex bem definido, enquanto que em C. ochracea os grânulos são mais globulares, opacos e com um córtex quase indistinto.

Distribuição: Conhecida somente para a localidade tipo: Brasil, Santa Catarina (Gumboski \& Eliasaro 2011a).

Habitat: Embora possa ser encontrada formando aglomerados conspícuos, a espécie é rara na área de estudo. Foi encontrada somente em costão rochoso, sobre rocha granítica, em áreas bem iluminadas e em locais expostos. Ocorre isolada de outras espécies do gênero.

Espécimes examinados: BRASIL. Santa Catarina: Bombinhas, Praia de Mariscal, costão rochoso ao norte da praia, 26 $6^{\circ} 13^{\prime} \mathrm{S}, 48^{\circ} 29^{\prime} \mathrm{O}, 19-\mathrm{II}-2010$, E. Gumboski \& F. Beilke 1717, 1718 (UPCB).

Cladonia merochlorophaea Asahina, J. Jap. Bot. 16: 713. 1940. Tipo: ALEMANHA. Niedersachsen: Oldenburg, Oldenburg Sand, 1918, Sandstede s.n., Sandstede: Cladon. Exs. 389 (lectótipo TNS, designado por Ahti (1993); isolectótipos B, FH, H, UPS).

Figura 6

Talo primário: persistente, composto por esquâmulas, 1,0-4,0 $\mathrm{mm}$ de comprimento, 0,5-1,0 $\mathrm{mm}$ de largura, lobadas, geralmente não recortadas, sem sorédios, margens lisas, sem rizinas; superfície superior lisa, pouco lustrosa, esverdeada, sem pruína; superfície inferior levemente aracnoide, branca; córtex 20-50 $\mu \mathrm{m}$ de espessura, medula 50-220 $\mu \mathrm{m}$ de espessura; picnídios ausentes. Talo secundário: $0,6-2,5 \mathrm{~cm}$ de altura, 0,5-1,5 $\mathrm{mm}$ de espessura, esverdeado a raramente marrom escurecido, cifoso, cifas simples, 1,5-4,0 mm de diâmetro, às vezes com uma ou duas ramificações cifosas originadas da margem da cifa, sem sorédios, somente grânulos e filídios presentes na parte interna, base não melanótica, porém algumas bases necróticas apresentam coloração marrom escurecido, perfurações ausentes; superfície corticada-areolada, rugosa, tornando-se verrucosa em podécios mais desenvolvidos, com espaços ecorticados principalmente na metade superior e dentro da cifa, sem sorédios, grânulos e filídios presentes principalmente dentro da cifa, esquâmulas presentes principalmente em cifas mais desenvolvidas, geralmente na metade basal e também ao longo da margem da cifa, lobadas, 0,4-0,7 mm de comprimento, $0,3-0,5(-0,8) \mathrm{mm}$ de largura; córtex com até $10 \mu \mathrm{m}$ de espessura, medula 40-90 $\mu \mathrm{m}$ de espessura, estereoma hialino a amarronzado, 50-70(-100) $\mu \mathrm{m}$ de espessura, canal central levemente papilado, 450-800 $\mu \mathrm{m}$ de diâmetro; discos himeniais ausentes; picnídios ausentes.

Química: Testes de coloração: K-, C-, KC-, UV-. CCD: Ácido merocloroféico e uma substância não identificada com Rf C aproximado de 25.

Cladonia merochlorophaea é caracterizada por possuir o talo primário esquamuloso, persistente, podécios constantemente cifosos com superfície corticada areolada, rugosa a verrucosa, sem sorédios, com grânulos, filídios e esquâmulas presentes, e por produzir ácido merocloroféico (Burgaz \& Ahti 2009).

Esta espécie é morfologicamente muito similar a Cladonia pyxidata (L.) Hoffm. por apresentar podécio cifoso com superfície corticada areolada, e com presença de grânulos, filídios e esquâmulas (Vainio 1894, Swinscow \& Krog 1988, Ahti \& Hammer 2002). Contudo, C. merochlorophaea produz ácido merocloroféico como composto principal embora possa apresentar também ácido fumarprotocetrárico como composto acessório, ao passo que $C$. pyxidata produz somente ácido fumarprotocetrárico (Swinscow \& Krog 1988, Ahti \& Hammer 2002)

Cladonia novochlorophaea (Sipman) Brodo $\&$ Ahti apresenta podécios cifosos e corticados tal qual C. merochlorophaea (Fleig et al. 1995, Ahti 2000, Burgaz \& Ahti 2009). No entanto, Ahti (2000) mencionou que as espécies são bem diferenciadas quanto à produção de compostos secundários, pois C. merochlorophaea produz ácido merocloroféico e C. novochlorophaea produz ácido sequicaico e ácido homosequicaico. Somado a isso, Burgaz \& Ahti (2009) citaram que C. merochlorophaea possui a superfície do podécio rugosa a verrucosa e de coloração esverdeada, enquanto que $C$. novochlorophaea possui a superfície do podécio verruculosa e com coloração enegrecida.

Outras espécies similares por apresentarem po-décios cifosos e com superfície corticada areolada são Cladonia ochrochlora Flöerke e C. chlorophaea (Flörke) Sprengel, entretanto, segundo Fleig et al. (1995) e Ahti (2000), ambas produzem ácido fumarprotocetrárico. Além disto, C. ochrochlora geralmente possui a metade superior do podécio completamente sorediada e o podécio de $C$. chlorophaea vai se tornando ecorticado com o desenvolvimento, além de apresentar grânulos sorediosos, características suficientemente distintas de C. merochlorophaea. 
Distribuição: Cladonia merochlorophaea é subcosmopolita, com distribuição desde o Ártico até as regiões tropicais (Ahti 2000, Burgaz \& Ahti 2009). Conhecida para a Oceania, Ásia, Europa, América do Norte e América do Sul, na Colômbia, Peru e Venezuela (Asahina 1940, Thomson 1967 apud Archer 1992, Ahti 1976, Galloway 1985, Ahti 2000, Flakus et al. 2008). No Brasil, até então era citada somente para o RS (Fleig et al. 1995), caracterizando-se esta como a segunda citação para o país e a primeira citação para o Estado de Santa Catarina.

Habitat: De acordo com Ahti (2000) a espécie ocorre geralmente em regiões com elevada altitude, de 900 a $4.100 \mathrm{~m}$, sendo que apesar da ampla distribuição, esta espécie é rara e subamostrada. $\mathrm{Na}$ área de estudo foi raramente encontrada, sendo que ainda em algumas populações muito pequenas, principalmente em restingas arbustivas, sombreadas, sobre solo arenoso e isoladas de outras espécies de fungos liquenizados. Fleig et al. (1995) citaram que a espécie também pode ser encontrada em gretas de rochas ou na base de troncos velhos.

Espécimes examinados: BRASIL. SANTA CATARINA: São Francisco do Sul, Parque Estadual do Acaraí, restinga, $26^{\circ} 15^{\prime} \mathrm{S}, 48^{\circ} 31^{\prime} \mathrm{O}, 17-\mathrm{III}-2009$, E. Gumboski 853 (UPCB), restinga, $26^{\circ} 23^{\prime} \mathrm{S}, 48^{\circ} 33^{\prime} \mathrm{O}, 18-\mathrm{IV}-2009$, E. Gumboski 1305 (UPCB), restinga, 10-IV-2010, E. Gumboski 1879 (UPCB); Laguna, área ao lado da rodovia BR-101, restinga, $28^{\circ} 24^{\prime} \mathrm{S}, 48^{\circ} 47^{\prime} \mathrm{O}$, 9-III-2009, E. Gumboski 752b (UPCB).

Espécimes adicionais examinadas: BRASIL. Rio Grande do Sul: Bagé, Casa de Pedra, $14 \mathrm{~km} \mathrm{em}$ vicinal paralela a BR 153, 4-XI-1989, M. Fleig 4054 (ICN).

Cladonia ochracea L. Scriba, Cladon. Exs. 1006. 1923. Tipo: BRASIL. Rio Grande Do Sul: Porto Alegre, 1907, Stier s.n. (lectótipo H, designado por Ahti (1993); isolectótipos B, BM, FH, G, M, UPS, US).

Figura 7

Talo primário: persistente a evanescente, composto por esquâmulas, 2,0-4,0 mm de comprimento, 0,5-1,5 mm de largura, laciniadas, recortadas, sem sorédios, margens crenadas a lisas, sem rizinas; superfície superior lisa, suavemente lustrosa, esverdeada a pardacenta, raramente pruinosa; superfície inferior aracnoide, branca; córtex 10-40 $\mu \mathrm{m}$ de espessura, medula 40-120 $\mu \mathrm{m}$ de espessura; picnídios ausentes.
Talo secundário: $1,0-3,4 \mathrm{~cm}$ de altura, 0,4-0,9 $\mathrm{mm}$ de espessura, esbranquiçado a esverdeado, cifoso a estreito cifoso, pouco ramificado, as ramificações originam-se principalmente na margem das cifas, cifas quase constantes, com 1,0-2,0 mm de diâmetro, interior corticado e geralmente sem propágulos, base não melanótica, perfurações ausentes; superfície corticada-areolada geralmente até metade do podécio, às vezes totalmente corticada, escabrosa, as partes mais antigas geralmente ecorticadas e ainda mais escabrosas, sem sorédios, porém muitos grânulos podem ser facilmente confundidos com sorédios, geralmente presentes na porção basal, presença também de esquisídios, filídios, esquâmulas laciniadas, recortadas ou não, até $1,5 \mathrm{~m}$ de comprimento; córtex (0-)5-20 $\mu \mathrm{m}$ de espessura, medula 40-80 $\mu \mathrm{m}$ de espessura, estereoma hialino, 50-110 $\mu \mathrm{m}$ de espessura, canal central pouco ranhurado e suavemente papilado, 450-750 $\mu \mathrm{m}$ de espessura; discos himeniais muito comuns, geralmente apicais em pequenos ramos originados na margem das cifas, formando pequenos aglomerados, marrom a marrom-claros, ascósporos fusiformes, $11-15 \times 3-5 \mu \mathrm{m}$; picnídios comuns, marginais nas cifas, negros, piriformes, conídios levemente curvados, 7-12 $\times 1 \mu \mathrm{m}$.

Química: Testes de coloração: K-, C-, KC-, UV-. CCD: Ácido fumarprotocetrárico.

Cladonia ochracea é caracterizada pelo podécio simples a pouco ramificado, cifoso, corticado na região basal às vezes atingindo até a metade da altura do podécio, muitas esquâmulas presentes, tornando-se escabroso principalmente na porção superior com muitos grânulos, filídios e esquisídios, e também pela produção de ácido fumarprotocetrárico (Fleig et al. 1995).

Cladonia ramulosa é muito similar a C. ochracea, pois ambas apresentam podécios cifosos, corticados, comumente com esquâmulas, discos himeniais marrons e produzem ácido fumarprotocetrárico. Entretanto, C. ochracea apresenta a superfície do podécio escabrosa, com filídios, esquisídios e comumente com áreas ecorticadas (Ahti 2000), enquanto que C. ramulosa possui o podécio principalmente corticado, característica que se torna mais evidente quando o mesmo está fértil, superfície rugosa e não apresenta filídios e esquisídios.

Outra espécie muito próxima é Cladonia pulverulenta (L. Scriba) Ahti. Ambas possuem os podécios cifosos, corticados e com áreas, principalmente na porção superior, ecorticadas, também apresentam filídios e esquisídios (Ahti 2000). 

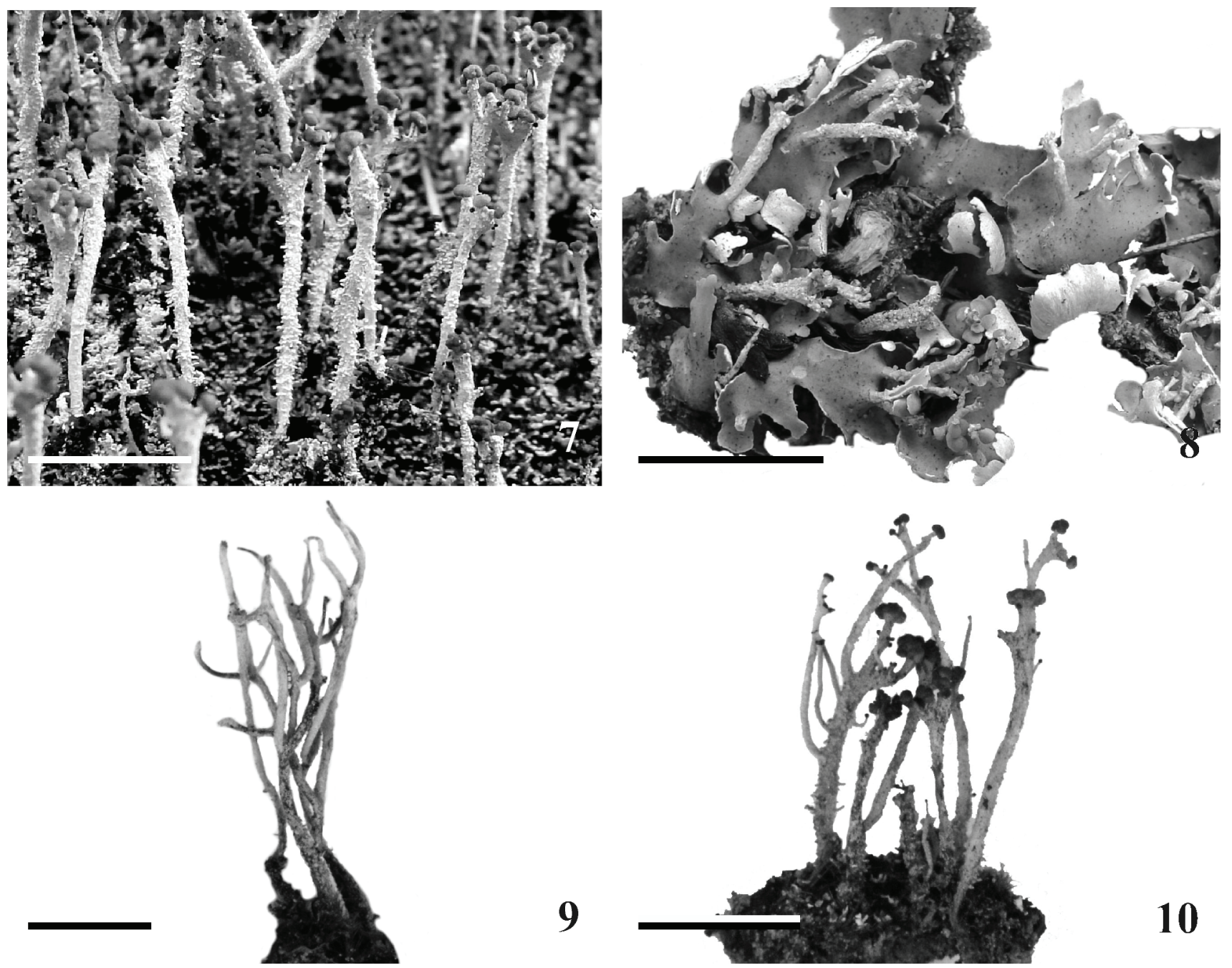

10
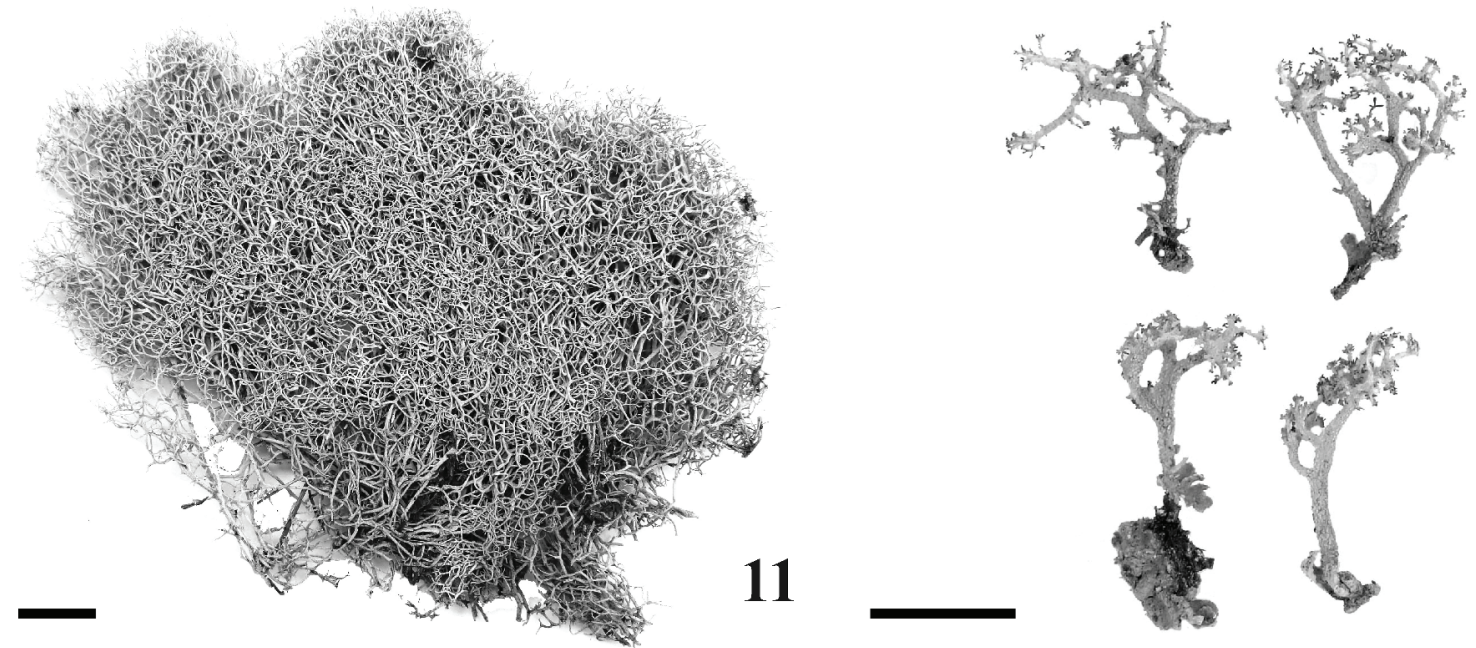

Figuras 7-12: 7. Cladonia ochracea (E. Gumboski 2013). 8. C. pityrophylla (E. Gumboski 778). 9. C. polyscypha (F. Beilke s.n.). 10. C. ramulosa (M. Dal-Forno 238). 11. C. signata (J. Sonehara s.n.). 12. C. solida (E. Gumboski 2015). Barras de escala $=1 \mathrm{~cm}$.

Figures 7-12: 7. Cladonia ochracea (E. Gumboski 2013). 8. C. pityrophylla (E. Gumboski 778). 9. C. polyscypha (F. Beilke s.n.). 10. C. ramulosa (M. Dal-Forno 238). 11. C. signata (J. Sonehara s.n.). 12. C. solida (E. Gumboski 2015). Scale bars $=1 \mathrm{~cm}$. 
No entanto, C. pulverulenta apresenta a base necrótica vermelha amarronzada, às vezes com estereoma melanótico e geralmente possui o podécio sorediado (Ahti 2000), enquanto que $C$. ochracea não possui a base melanótica e não apresenta sorédios verdadeiros (Fleig et al. 1995).

Distribuição: Conhecida apenas para o centro-sul da América do Sul, na Argentina, Paraguai e Uruguai (Ahti 2000) e Brasil, para os Estados do ES, MS, MG, RJ, RS, SC e SP (Osorio \& Fleig 1991, Ahti 2000). Esta é a primeira citação para o Estado do Paraná.

Habitat: Cladonia ochracea ocorre desde o nível do mar até 1.900 metros de altitude (Ahti 2000). Na área de estudo foi encontrada principalmente em restingas. A ocorrência em costões rochosos foi mais discreta, com talos geralmente de tamanhos menores e formando pequenos aglomerados. Em restinga, Cladonia ochracea geralmente forma aglomerados bem evidentes, principalmente próximas a borda de restingas arbustivas onde a iluminação é de moderada a intensa. É frequentemente encontrada entre podécios de $C$. didyma, C. subradiata, C. ramulosa, C. subsquamosa, C. solida e C. crispatula (Nyl.) Ahti. O maior "tapete" formado pela espécie, juntamente com Cladonia solida, C. didyma e C. ramulosa foi de $10 \mathrm{~m}^{2}$ em um barranco argilo-arenoso presente no Parque Estadual do Acaraí, em Santa Catarina. Embora ocorra principalmente sobre o solo arenoso ou serapilheira, foi encontrada colonizando vários substratos como madeira em decomposição, mourões de madeira, associada a musgos e sobre rochas, nesta última, com menor frequência. Até sobre pedaços de pano foi encontrada.

Espécimes selecionados examinados: BRASIL. PARANÁ: Guaraqueçaba, Ilha das Peças, restinga, 26-X-2003, C.G. Donha 1345 (UPCB), 20-IV-2004, S. Eliasaro 2757, 2758 (UPCB); Paranaguá, Parque Estadual da Ilha do Mel, restinga, $25^{\circ} 31^{\prime} \mathrm{S}, 48^{\circ} 18^{\prime} \mathrm{O}$, 27-VIII-2009, E. Gumboski \& S. Eliasaro 1581 (UPCB), costão rochoso na Praia de Fora, $25^{\circ} 32^{\prime} \mathrm{S}$, $48^{\circ} 17^{\prime} \mathrm{O}, 27-\mathrm{VIII}-2009$, E. Gumboski \& S. Eliasaro 1653 (UPCB); Pontal do Paraná, Pontal do Sul, restinga, 5-IX-2007, M. Dal-Forno 683 (UPCB); Matinhos, Ilha das Tartarugas, costão rochoso, $25^{\circ} 51^{\prime} \mathrm{S}, 48^{\circ} 32^{\prime} \mathrm{O}, 21-\mathrm{III}-2010$, E. Gumboski \& F. Beilke 1830, 1833 (UPCB). Santa Catarina: São Francisco do Sul, Morro João Dias, costão rochoso, $26^{\circ} 10^{\prime} \mathrm{S}, 48^{\circ} 31^{\prime} \mathrm{O}, 5-\mathrm{III}-2009$, E. Gumboski 662, 681 (UPCB), Parque Estadual do Acaraí, restinga, $26^{\circ} 15^{\prime} \mathrm{S}, 48^{\circ} 31^{\prime} \mathrm{O}, 17-\mathrm{III}-2009$, E. Gumboski 808, 815,829 (UPCB); Bombinhas, Praia de Mariscal, costão rochoso ao norte da praia, $26^{\circ} 13^{\prime} \mathrm{S}, 48^{\circ} 29^{\prime} \mathrm{O}$, 19-II-2010, E. Gumboski \& F. Beilke 1722 (UPCB); Laguna, área ao lado da rodovia BR-101, restinga, $28^{\circ} 24^{\prime}$ 'S, 48 $47^{\circ}$ 'O, 9-III-2009, E. Gumboski 779 (UPCB).

Cladonia pityrophylla Nyl., Flora 57: 70. 1874. Tipo: BRASIL. ParÁ: Santarém, foz do Rio Tapajós, 1849-1855, Spruce, Lich. Amaz. And. 26 (holótipo H-NYL 38843; isótipos BM, G, G-DC, PC, TUR-V 19989).

Figura 8

Talo primário: persistente, muito desenvolvido, composto por esquâmulas, $10-18(-25) \mathrm{mm}$ de comprimento, 4,0-8,0 $\mathrm{mm}$ de largura, lobadas, imbricadas, lobos arredondados, irregularmente recortados, sem sorédios, margens lisas a crenadas, sem rizinas; superfície superior lisa, lustrosa, esverdeada a ocre, sem pruína; superfície inferior suavemente aracnoide a lisa, branca, porém algumas partes voltadas para cima podem tornar-se amarronzadas; córtex 30-70 $\mu \mathrm{m}$ de espessura, medula 100-340 $\mu \mathrm{m}$ de espessura; picnídios ausentes. Talo secundário: 1,0-6,0 $\mathrm{mm}$ de altura, 0,3-0,9 $\mathrm{mm}$ de espessura, esbranquiçado a acinzentado, simples a pouco ramificado principalmente do terço superior, ápices subulados, acifosos, porém, a axila de algumas ramificações pode apresentar aspecto cifóide, base não melanótica, perfurações ausentes; superfície corticada-areolada, aracnoide a rugosa, sem sorédios e grânulos, esquâmulas orbiculares, algumas com até $1,0 \mathrm{~mm}$ de diâmetro, distribuídas aleatoriamente sobre o podécio; córtex 0-10(-25) $\mu \mathrm{m}$ de espessura, medula 25-80(-160) $\mu \mathrm{m}$ de espessura, estereoma hialino, 75-125(-175) $\mu \mathrm{m}$ de espessura, canal central liso a levemente sulcado, 600-900 $\mu \mathrm{m}$ de diâmetro; discos himeniais incomuns, apicais, marrons claros, imaturos, ascósporos ausentes; picnídios frequentes, apicais, marrons a marrons claros, piriformes, mucilagem hialina, conídios levemente curvados, $4-6 \times 1 \mu \mathrm{m}$.

Química: Testes de coloração: $\mathrm{K}+$ amarelo sujo, C-, KC-, UV-. CCD: Ácido fumarprotocetrárico, uma substância não identificada com Rf C aproximado de 80 e um pigmento com Rf C aproximado de 90.

De acordo a descrição de Vainio (1894), Cladonia pityrophylla é caracterizada pelas esquâmulas 
primárias largas, lobadas, sem rizinas marginais, podécios laminais, simples a pouco ramificados, em parte ecorticados, sem sorédios, geralmente com esquâmulas buladas a globosas. Bem como pela produção de ácido fumarprotocetrárico (Fleig et al. 1995).

Cladonia pityrophylla é similar a C. subcariosa Nyl. por ambas possuírem esquâmulas primárias bem desenvolvidas e largas (Ferraro \& Ahti 1987). Entretanto, Fleig et al. (1995) citaram que C. pityrophylla possui podécios geralmente simples, subulados, pouco desenvolvidos, em parte ecorticados e geralmente produz ácido fumarprotocetrárico. Enquanto que C. subcariosa apresenta podécios clavados, continuamente corticados (Vainio 1894) e, segundo Ahti (2000) e Burgaz \& Ahti (2009), apresenta seis quimiotipos distintos: o primeiro com atranorina e ácido norestíctico; o segundo com ácido estíctico; o terceiro com ácido norestíctico; o quarto com ácido fumarprotocetrárico; o quinto com ácido norestíctico e ácido fumarprotocetrárico; e o sexto com ácido psorômico. Sendo que o quimiotipo que apresenta ácido fumarprotocetrárico como principal composto tem a distribuição restrita na República Dominicana, leste da América do Norte e leste da Ásia (Ahti 2000).

Cladonia megaphylla Ahti \& Marcelli também apresenta esquâmulas primárias bem desenvolvidas e produz ácido fumarprotocetrárico. Entretanto, pode ser diferenciada de $C$. pityrophylla por apresentar, de acordo com descrição em Ahti (2000), esquâmulas primárias alongadas, podécios com ramificações apicais curtas e axilas geralmente perfuradas.

Embora Cladonia latiloba possua esquâmulas primárias bem desenvolvidas e alongadas, a mesma apresenta os podécios clavados e frequentemente produz atranorina. Características bem distintas de C. pityrophylla.

Pode ser confundida com C. ceratophylla por ambas possuírem esquâmulas primárias bem desenvolvidas e por, embora não juntas, ocorrerem desde o litoral até o planalto (ver comentários em Cladonia ceratophylla).

Distribuição: Espécie tropical (Ahti 2000) é conhecida somente para a América do Sul, na Argentina, Guiana, Paraguai e Venezuela (Ferraro \& Ahti 1987, Sipman $\&$ Aptroot 1992, Ahti 2000). No Brasil é citada para os Estados da BA, DF, MG, MT, PA, PB, PE, PR, RJ, RR, RS, SC, SE e SP (Müller 1881, Vainio 1894, Osorio \& Fleig 1988b, Ahti et al. 1993, Ahti 2000).
Habitat: Cladonia pityrophylla ocorre desde o nível do mar até 2.500 metros de altitude (Ahti 2000). Não é uma espécie facilmente encontrada na área de estudo. Foi localizada sempre sobre substrato arenoso, mesmo em costões rochosos não cresce diretamente sobre as rochas, estava presente próxima a vegetação ou em áreas onde ocorre o acúmulo de sedimentos arenosos. Ocorre geralmente em áreas bem iluminadas e dificilmente dividindo espaço com outras espécies, como Cladonia didyma.

Espécimes examinados: BRASIL. PARANÁ: Matinhos, Ilha das Tartarugas, costão rochoso, $25^{\circ} 51^{\prime} \mathrm{S}, 48^{\circ} 32^{\prime} \mathrm{O}$, 21-III-2010, E. Gumboski \& F. Beilke 1838 (UPCB). Santa Catarina: São Francisco do Sul, Morro da Enseada, costão rochoso, $26^{\circ} 13^{\prime} \mathrm{S}, 48^{\circ} 29^{\prime} \mathrm{O}$, 28-IV-2008, E. Gumboski 162 (UPCB); Laguna, área ao lado da rodovia BR-101, restinga, $28^{\circ} 24^{\prime} \mathrm{S}, 48^{\circ} 47^{\prime} \mathrm{O}$, 9-III-2009, E. Gumboski 754, 778, 784 (UPCB), 25-VIII-2007, E. Gumboski 985 (UPCB).

Cladonia polyscypha Ahti \& L. Xavier Filho, Trop. Bryol. 7: 61. 1993. Tipo: BRASIL. PARAíBA: Mun. Alhandra, ca. $30 \mathrm{Km}$ S de São João Pessoa, 120 m, 1987, Ahti \& Xavier Filho 45698 (holótipo H; isótipo JPB).

Figura 9

Talo primário: evanescente, composto por esquâmulas, 0,8-1,3 $\mathrm{mm}$ de comprimento, $0,5-1,0 \mathrm{~mm}$ de largura, lobadas, recortadas ou não, sem sorédios, margens suavemente crenadas, sem rizinas; superfície superior lisa, pouco lustrosa, esverdeada a acinzentada, sem pruína; superfície inferior aracnoide, branca; córtex 20-50 $\mu \mathrm{m}$ de espessura, medula 50-110 $\mu \mathrm{m}$ de espessura; picnídios ausentes. Talo secundário: 2,0-4,5 $\mathrm{cm}$ de altura, $0,5-1,5 \mathrm{~mm}$ de espessura, pouco ramificado com até cinco ramificações, ápices principalmente estreito cifosos, às vezes subulados, cifas com até $1,3 \mathrm{~mm}$ de diâmetro quando desenvolvidas, margem denteada, às vezes com até quatro ramos marginais, sorediadas, base suave a distintamente melanótica, perfurações ausentes; superfície principalmente ecorticada, aracnoide, córtex presente na região basal, às vezes atingindo quase metade do podécio, também presente dentro e ao redor da cifa, geralmente corticado-areolado, superfície sorediada ao longo do podécio, sorédios farinosos a granulosos, sem grânulos, esquâmulas dispersas aleatoriamente no podécio, inconspícuas, laciniadas com até $0,8 \mathrm{~mm}$ de comprimento; córtex 10-27 $\mu \mathrm{m}$ de espessura, medula 30-60(-120) $\mu \mathrm{m}$ 
de espessura, estereoma hialino a melanótico, (50-)100-160 $\mu \mathrm{m}$ de espessura, canal central ranhurado e papilado, 400-1.000 $\mu \mathrm{m}$ de diâmetro; discos himeniais infrequentes, apicais e nas margens das cifas, marrons claros, globosos, até $0,8 \mathrm{~mm}$ de diâmetro, ascósporos fusiformes, 10-15 × 3-5 $\mu \mathrm{m}$; picnídios comuns, geralmente na margem das cifas, poucos ficam localizados lateralmente no podécio, negros, piriformes, conídios falciformes, $10-12 \times 1 \mu \mathrm{m}$.

Química: Testes de coloração: $\mathrm{K}+$ amarelo sujo, C-, KC-, UV-. CCD: Ácido fumarprotocetrárico.

Cladonia polyscypha caracteriza-se por apresentar podécios ecorticados, estreitos cifosos, sorediados e pela produção de ácido fumarprotocetrárico (Ahti et al. 1993). A base melanótica é característica marcante e distintiva da espécie (Ahti 2000).

Cladonia subradiata é muito semelhante por apresentar podécio ecorticado, sorediado e por produzir ácido fumarprotocetrárico. Entretanto, a mesma não possui base melanótica, apresenta sorédios isidióides na porção basal e geralmente possui os ápices subulados, ao passo que C. polyscypha, como também observado no espécime proveniente de São Paulo, possui os sorédios granulares e geralmente com ápices estreito cifosos, além da distinta base melanótica.

Cladonia ochracea apresenta o podécio cifoso, corticado na porção basal e produz ácido fumarprotocetrárico, similar a C. polyscypha. Entretanto, são diferenciadas pela base necrótica melanótica e produção de sorédios ao longo do podécio em C. polyscypha. Enquanto que em C. ochracea a base do podécio não é melanótica e também não são produzidos sorédios verdadeiros.

São mencionadas pela primeira vez a forma e as dimensões dos ascósporos produzidos por C. polyscypha, que, como característica comum ao gênero, possui os ascósporos bastante similares às demais espécies de Cladonia.

Distribuição: Conhecida somente para a América do Sul, na Venezuela, Guiana e Guiana Francesa (Ahti 2000). No Brasil, é citada para os Estados do AM, PB, PE, RJ, SE e SP (Ahti et al. 1993, Ahti 2000). Esta é a primeira citação de Cladonia polyscypha para o Estado de Santa Catarina, o que amplia o limite austral da mesma.

Habitat: Segundo Ahti (2000), Cladonia polyscypha é encontrada desde o nível do mar até 1.100 metros de altitude, ocorrendo principalmente em solos arenosos. $\mathrm{Na}$ área de estudo foi encontrada somente em restinga arbustiva da cidade de Itapoá, sobre solo arenoso e em área bem iluminada. Geralmente encontrada isolada de outras espécies do gênero e frequentemente formando aglomerados conspícuos, principalmente devido à altura do podécio.

Espécimes examinados: BRASIL. Santa Catarina: Itapoá, Samambaial, restinga, 13-II-2010, F. Beilke s.n. (UPCB 71422).

Espécimes adicionais examinados: BRASIL. São Paulo: Itanhaém, ca. $8 \mathrm{~km}$ WSW de Itanhaém na rodovia SP-56, 26-I-1987, T. Ahti \& M.P. Marcelli 46009 (SP).

Cladonia ramulosa (With.) J.R. Laundon, Lichenologist 16: 225. 1984. Tipo: INGLATERRA. LONDRES: Greenwich, WoolwichHeath, Dillenius s.n. (epítipo OXF, designado por Laundon (1984)).

Figura 10

Talo primário: persistente, composto por esquâmulas, 1,5-3,0 mm de comprimento, 0,5-1,5 mm de largura, lobuladas, imbricadas, pouco recortadas, sem sorédios, margem crenada, sem rizinas; superfície superior lisa, pouco lustrosa, esverdeada a cinza amarelada, sem pruína; superfície inferior aracnoide, branca; córtex 10-32 $\mu \mathrm{m}$ de espessura, medula 40-140 $\mu \mathrm{m}$ de espessura; picnídios frequentes, laminais, negros, globosos, constritos na base, conídios levemente curvados, $6-7 \times 1 \mu \mathrm{m}$. Talo secundário: $0,5-2,0 \mathrm{~cm}$ de altura, 0,4-0,7 $\mathrm{mm}$ de espessura, esverdeado a acinzentado, marrom quando exposto a luminosidade direta, simples a pouco ramificado, cifoso, cifas nem sempre evidentes, 0,4-1,6 mm de diâmetro, às vezes com uma a três ramificações marginais, capitadas, internamente corticadas, sem sorédios e grânulos, base não melanótica, perfurações ausentes; superfície corticada, rugosa a raro verruculosa, sem sorédios, granulosa principalmente em talos mais jovens, geralmente com poucas esquâmulas localizadas principalmente na porção basal, lobuladas a laciniadas, recortadas ou não, até $1,0 \mathrm{~mm}$ de comprimento, poucas vezes recobrem todo o talo; córtex 10-20 $\mu \mathrm{m}$ de espessura, medula 50-120 $\mu \mathrm{m}$ de espessura, estereoma hialino a pardacento, 50-100(-210) $\mu \mathrm{m}$ de espessura, canal central ranhurado e papilulado, ficando mais evidente próximo ao ápice, 300-600 $\mu \mathrm{m}$ de diâmetro; discos himeniais muito comuns, apicais, geralmente poucos por ápice, marrons a marrom escurecidos, ascósporos fusiformes, $14-17 \times 3-4 \mu \mathrm{m}$; picnídios 
comuns, raros, marginais nas cifas, negros, globosos, constritos na base, conídios levemente curvados, $6-7 \times 1 \mu \mathrm{m}$.

Química: Testes de coloração: K- ou K+ amarelo sujo, C-, KC-, UV-. CCD: Ácido fumarprotocetrárico.

Segundo Ahti (2000), Cladonia ramulosa é bastante variável morfologicamente e de difícil definição, contudo, pode ser caracterizada pelo podécio simples, estreitamente cifoso, corticado, com superfície rugosa a verruculosa, geralmente capitado, sem sorédios, com grânulos e esquâmulas presentes, com um disco himenial subgloboso e marrom (Swinscow \& Krog 1988, Fleig et al. 1995, Burgaz \& Ahti 2009).

Cladonia ramulosa é semelhante a $C$. pseudopityrea Vain. por ambas possuírem os podécios corticados, cifosos, esquamulosos, discos himeniais marrons e pela produção de ácido fumarprotocetrárico. Contudo, Burgaz \& Ahti (2009) mencionam que C. ramulosa possui os podécios mais espessados e com córtex principalmente contínuo, enquanto que C. pseudopityrea possui podécios mais delicados e com córtex descontínuo.

Cladonia ochracea também é semelhante por apresentar o podécio corticado, cifoso, com superfície verruculosa e produção de ácido fumarprotocetrárico (ver comentários em C. ochracea).

Assim como Vainio (1894), Burgaz \& Ahti (2009) mencionaram que Cladonia ramulosa pode apresentar, mesmo que raramente, sorédios granulosos na superfície do podécio. Tal fato pode levar a confusão com C. ochrochlora que também possui podécios cifosos, corticados e com sorédios (Burgaz \& Ahti 2009). Contudo, C. ramulosa possui a superfície do podécio corticada em toda sua extensão, como também observado no espécime (S. Eliasaro 2044) oriundo do cerrado paranaense. Enquanto que $C$. ochrochlora apresenta sorédios farinosos e o córtex localiza-se principalmente na metade inferior do podécio (Ahti \& Hammer 2002).

Alguns exemplares coletados em costões rochosos (e.g. E. Gumboski 502, 530, E. Gumboski et al. 1865) apresentaram algumas características um pouco diferenciadas dos demais. As esquâmulas primárias são densamente agrupadas com 0,3 a 1,5 mm de comprimento por 0,2 a 1,0 $\mathrm{mm}$ de largura, e são, às vezes, a única parte presente do talo, sendo que os podécios vão se tornando ecorticados ao longo do desenvolvimento, deixando o córtex restrito a porção basal. Porém, de acordo com alguns autores (e.g. Fleig et al. 1995, Ahti 2000, Burgaz \& Ahti 2009) Cladonia ramulosa é uma espécie cosmopolita que apresenta uma alta plasticidade fenotípica, sendo que os exemplares mencionados anteriormente correspondem a variações morfológicas da mesma. Análises moleculares podem revelar um complexo de espécies mantido sob o nome C. ramulosa.

Distribuição: De acordo com Burgaz \& Ahti (2009), Cladonia ramulosa é cosmopolita, sendo conhecida para a Oceania, Ásia, Europa, África, América do Norte, América Central (Vainio 1894 - como Cladonia pityrea (Flörke) Fr.) e América do Sul, na Argentina, Colômbia, Paraguai, Peru (como Cladonia pityrea), Uruguai e Venezuela (Ferraro \& Ahti 1987, Ahti 2000). No Brasil, é citada para os Estados do AM, MG, PA, PE, PR, RJ, RS, RR, SC e SP (Osorio \& Fleig 1988a, Ahti 2000, Ahti et al. 1993).

Habitat: Ocorre desde o nível do mar até aproximadamente 2.000 metros de altitude (Ahti 2000). $\mathrm{Na}$ área de estudo foi encontrada tanto em restingas quanto em costões rochosos e, embora seja comum nos ambientes, nem sempre é fácil localizá-la, principalmente pelo fato de que raramente forma grandes colônias. Ocorre sobre solo arenoso, serapilheira, mourão de madeira e galhos caídos. Cladonia ramulosa pode ser encontrada tanto em áreas sombreadas quanto em áreas bem iluminadas, tais como restingas herbáceas e áreas expostas de costões. É comum entremear-se com podécios de diversas espécies, tais como: C. ceratophylla, C. crispatula, C. didyma, C. furfuracea, C. latiloba, C. subsquamosa e C. subradiata.

Espécimes selecionados examinados: BRASIL. PARANÁ: Guaraqueçaba, Parque Nacional do Superagüi, restinga, $25^{\circ} 27^{\prime} \mathrm{S}, 48^{\circ} 14^{\prime} \mathrm{O}, 8-\mathrm{IV}-2003$, S. Eliasaro \& C.G. Donha 2550, 2556 (UPCB); Paranaguá, Parque Estadual da Ilha do Mel, costão rochoso na Praia de

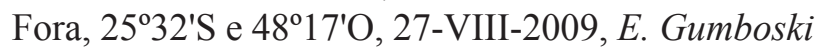
\& S. Eliasaro 1633 (UPCB); Pontal do Paraná, Pontal do Sul, restinga, 9-IX-2007, M. Dal-Forno 238 (UPCB). Santa Catarina: São Francisco do Sul, Morro da Enseada, costão rochoso, $26^{\circ} 13$ 'S, 48⒉'O, 19-VI-2008, E. Gumboski 502, 530 (UPCB), Morro João Dias, costão rochoso, $26^{\circ} 10^{\prime} \mathrm{S}, 48^{\circ} 31^{\prime} \mathrm{O}$, 5-III-2009, E. Gumboski 670 (UPCB), Parque Estadual do Acaraí, restinga, $26^{\circ} 15^{\prime} \mathrm{S}, 48^{\circ} 31^{\prime} \mathrm{O}, 17-\mathrm{III}-2009, E$. Gumboski 693, 874, 875, 895 (UPCB); Bombinhas, Praia de Mariscal, costão rochoso ao norte da praia, 
$26^{\circ} 13^{\prime} \mathrm{S}, 48^{\circ} 29^{\prime} \mathrm{O}, 19-\mathrm{II}-2010$, E. Gumboski \& F. Beilke 1724 (UPCB); Florianópolis, Costão do Santinho, costão rochoso, $27^{\circ} 26^{\prime} \mathrm{S}, 48^{\circ} 22^{\prime} \mathrm{O}, 18$-IV-2010, E. Gumboski, A.C.L. Gerlach, L.F. Oliveira 1865 (UPCB); Laguna, área ao lado da rodovia BR-101, restinga, $28^{\circ} 24^{\prime} \mathrm{S}, 48^{\circ} 47^{\prime} \mathrm{O}$, 9-III-2009, E. Gumboski 776 (UPCB).

Espécime adicional examinado: BRASIL. Paraná: Jaguariaíva, Parque Estadual do Cerrado, XII-1998, S. Eliasaro 2044 (UPCB).

Cladonia signata (Eschw.) Vain., Meddelan Soc. Fauna Fl. Fenn. 14: 32. 1886. $\equiv$ Cladonia rangiferina [var.] signata Eschw. in Martius, Fl. Bras. Enum. Pl. 1(1):275. 1833. Tipo: BRASIL. Amazonas: Rio Cuieiras, $50 \mathrm{Km}$ rio acima, 1974, Ongley \& Ramos P21767 (neótipo INPA, designado por Ahti (1993); isótipos DUKE, $\mathrm{H}, \mathrm{M}, \mathrm{NY}$ ).

Figura 11

Talo primário: ausente. Talo secundário: aspecto geral subgloboso, 3,0-6,0 cm de diâmetro, 2,0-6,5 cm de altura, ramos 0,5-1,0 $\mathrm{mm}$ de espessura, esverdeado a cinza amarelado, densamente ramificado, ramificação dicotômica, anisotômica, às vezes com ramificações tricotômicas, sem eixo principal evidente, porém alguns ramos mais espessados podem parecer principais, entrenós 2,0-6,0(-7,1) mm de comprimento, ápices subulados, acifosos, base não melanótica, perfurações geralmente ausentes, quando presentes são discretas, axilares, até $0,2 \mathrm{~mm}$ de diâmetro; superfície ecorticada, subaracnoidea a aracnoide, sem sorédios e grânulos, esquâmulas raramente presentes, geralmente na porção basal do podécio, lobadas, suavemente crenadas, diminutas, até $0,4 \mathrm{~mm}$ de comprimento; medula (0-)30-50 $\mu \mathrm{m}$ de espessura, estereoma hialino, (50-)80-120 $\mu \mathrm{m}$ de espessura, canal central levemente ranhurado a liso, (100-)300-500 $\mu \mathrm{m}$ de diâmetro; discos himeniais ausentes; picnídios ausentes.

Química: Testes de coloração: K-, C-, KC-, UV-. CCD: Ácido fumarprotocetrárico e uma substância não identificada com Rf C aproximado de 73.

Cladonia signata é uma das poucas espécies pertencentes ao Supergrupo Cladonia com podécio densamente ramificado (Ahti 2000, Stenroos et al. 2002a). É caracterizada também por não possuir um eixo principal distinto, por apresentar ramificações principalmente dicotômicas, superfície do podécio ecorticada, axilas geralmente fechadas (Vainio 1887, Santesson 1942) e pela produção de ácido fumarprotocetrárico (Ahti 2000).
Embora pertença a um gênero distinto, Carassea connexa (Vain.) S. Stenroos é similar a Cladonia signata por serem densamente ramificadas, com ramificações isotômicas e sem eixo principal distinto (Ahti 2000). Entretanto, segundo Stenroos et al. (2002b), Carassea connexa produz atranorina e possui o estereoma delicado, com 10 a $30 \mu \mathrm{m}$ de espessura, enquanto que Ahti (2000) citou que Cladonia signata produz ácido fumarprotocetrárico e possui o estereoma mais robusto, com 50 a $120 \mu \mathrm{m}$ de espessura.

Cladonia signata também pode ser confundida com outras espécies pertencentes ao Supergrupo Crustaceae, por apresentarem em comum o talo primário raramente presente e o podécio densamente ramificado e ecorticado. Segundo Burgaz \& Ahti (2009), as espécies pertencentes a este Supergrupo possuem o talo primário crustoso, e não esquamuloso como em Cladonia signata e os podécios geralmente possuem axilas perfuradas com um eixo principal distinto, características que facilmente separam a C. signata das demais.

Distribuição: É conhecida principalmente para a América do Sul, na Bolívia, Colômbia, Equador, Guiana, Peru, Suriname e Venezuela, com registro também para a Ásia (Sipman 1990, Ahti 2000). No Brasil é citada para os Estados do AM, BA, MG, PA, PR, RJ, SC e SP (Vainio 1887, Ahti 2000).

Habitat: Cladonia signata pode ser encontrada principalmente em áreas de baixa altitude (Ahti 2000). Na área de estudo a espécie apresentou uma distribuição bastante restrita, sendo encontrada somente em restingas e apenas no Paraná. Sempre sobre solo arenoso e com muita serapilheira, ocorrendo de forma isolada em áreas bastante sombreadas. Vainio (1887) acrescentou que a espécie pode ocorrer sobre rochas e raramente sobre lenho em decomposição.

Espécimes examinados: BRASIL. PARANÁ: Guara-queçaba, Ilha das Peças, restinga, $25^{\circ} 28^{\prime} \mathrm{S}, 48^{\circ} 17^{\prime} \mathrm{O}$, 20-III-2010, E. Gumboski \& F. Beilke 1802, 1814 (UPCB); Matinhos, Parque Estadual Rio da Onça, restinga, 27-IV-2004, J. Sonehara s.n. (UPCB 55787).

Cladonia solida Vain., Acta Soc. Fauna Fl. Fenn. 7(1): 246. 1890. Tipo: BRASIL. Minas Gerais: Antônio Carlos (Sítio), 1885, Vainio s.n. (lectótipo TUR-V 17216, designado por Ahti (1993)).

Figura 12

Talo primário: persistente a evanescente, composto por esquâmulas, 0,3-2,5(-4,0) $\mathrm{mm}$ de comprimento, 
$0,2-1,0(-2,0) \mathrm{mm}$ de largura, lobadas, geralmente recortadas, sem sorédios, margem lisa, sem rizinas; superfície superior lisa a levemente rugosa, pouco lustrosa, esverdeada, maculada ou não, máculas laminais, efiguradas, bem distintas em esquâmulas mais desenvolvidas, sem pruína; superfície inferior aracnoide, branca; córtex (10-)20-60 $\mu \mathrm{m}$ de espessura, medula 70-370 $\mu \mathrm{m}$ de espessura; picnídios ausentes. Talo secundário: $0,8-2,0 \mathrm{~cm}$ de altura, $0,5-0,9 \mathrm{~mm}$ de espessura, esverdeados a verde acinzentados, moderadamente ramificado, ramificações dicotômicas, anisotômicas, ocorrem principalmente a partir da metade superior, ápices subulados, acifosos, base não melanótica, perfurações ausentes; superfície corticada, verrucosa, sem sorédios e grânulos, porém em algumas partes o córtex com aspecto verrucoso pode parecer granuloso, esquâmulas comuns, em geral na metade inferior, lobadas, ascendentes, $0,5-0,9 \mathrm{~mm}$ de comprimento, 0,3-0,6(-1,0) $\mathrm{mm}$ de largura; córtex 10-20 $\mu \mathrm{m}$ de espessura, medula 50-100 $\mu \mathrm{m}$ de espessura, estereoma hialino, 500-900 $\mu \mathrm{m}$ de diâmetro, canal central geralmente ausente, porém, em regiões mais espessadas da base pode ocorrer um pequeno canal com no máximo $100 \mu \mathrm{m}$ de diâmetro; discos himeniais comuns, apicais, marrons claros, imaturos, ascósporos ausentes; picnídios comuns, apicais, marrons claros, ovoides, mucilagem ausente, conídios ausentes.

Química: Testes de coloração: K-, C-, KC-, UV-. CCD: Ácido fumarprotocetrárico e uma substância não identificada com Rf C aproximado de 20.

Cladonia solida é caracterizada pelo podécio sólido, pouco ramificado, ramificações principalmente na metade superior, dicotômicas, superfície corticada (Vainio 1894) e pela produção de ácido fumarprotocetrárico (Fleig et al. 1995). Na área de estudo esta espécie é bastante distinta das demais por ser a única a produzir podécios constantemente sólidos.

Vainio (1887) separou esta espécie em duas formas: Cladonia solida f. glabrata Vain., que não apresenta sorédios e C. solida f. leprifera Vain., que apresenta sorédios formados em estruturas tuberculares. Contudo, embora ambas as formas possam representar espécies distintas, na área de estudo nenhum espécime apresentou sorédios e, como o material tipo de Cladonia solida é a forma sem sorédios, não há razões para pensar que os espécimes encontrados pertençam à outra espécie.
Ahti (2000) também considerou ambas as formas como pertencentes à mesma espécie, e acrescentou que a presença eventual de sorédios parece não ser significante taxonomicamente para esta espécie.

Distribuição: É conhecida somente para a região centro-sul da América do Sul, no Paraguai (Ahti 2000). No Brasil é citada para os Estados de MG, PR, RJ, RS, SC e SP (Vainio 1887, Fleig et al. 1995, Ahti 2000, Gumboski \& Eliasaro 2011b).

Habitat: Cladonia solida, de acordo com Ahti (2000), ocorre desde o nível do mar até 1.200 metros de altitude. Na área de estudo apresentou uma distribuição bastante restrita, sendo encontrada somente na restinga do Parque Estadual do Acaraí, em São Francisco do Sul, onde formava um grande aglomerado sobre um barranco argilo-arenoso juntamente com podécios de Cladonia didyma, C. ochracea e C. ramulosa. Pequenos talos de C. ceratophylla e C. latiloba também foram encontrados. Fleig et al. (1995) acrescentaram que a espécie também pode ser encontrada sobre rocha.

Espécimes examinados: BRASIL. SANTA Catarina: São Francisco do Sul, Parque Estadual do Acaraí, restinga, sobre barranco argilo-arenoso, $26^{\circ} 20^{\prime} \mathrm{S}$, $48^{\circ} 33^{\prime} \mathrm{O}, 3$-VI-2010, E. Gumboski 2015 (UPCB).

Cladonia subradiata (Vain.) Sands., Abh. Naturwiss. Vereine Bremen 25:230.1922 三Cladonia fimbriata [var.] chondroidea [subvar.] subradiata Vain., Acta Soc. Fauna Fl. Fenn. 10: 338. 1894. Tipo: BRASIL. Minas Gerais: Caraça, 1885, Vainio s.n. (lectótipo TUR-V 19517, designado por Ahti (1993)).

\section{Figura 13}

Talo primário: persistente a evanescente, composto por esquâmulas, 0,5-2,0 mm de comprimento, 1,0-2,0 mm de largura, lobadas, recortadas, sem sorédios, margens crenadas, sem rizinas; superfície superior lisa, pouco lustrosa, esverdeadas a esbranquiçadas, sem pruína; superfície inferior aracnoide, branca; córtex 20-40 $\mu \mathrm{m}$ de espessura, medula 60-130 $\mu \mathrm{m}$ de espessura; picnídios ausentes. Talo secundário: $0,7-2,0 \mathrm{~cm}$ de altura, 0,4-0,9 $\mathrm{mm}$ de espessura, esbranquiçados a brancos esverdeados, simples, raramente com uma a duas ramificações, ápices subulados a geralmente com uma pequena cifa distal, cifas apicais, pequenas, suavemente denteadas com até 1,6 mm de diâmetro, sem ramificações marginais, base não melanótica, perfurações ausentes; superfície ecorticada, levemente 
aracnoide, córtex presente somente na base do podécio, totalmente sorediado, alguns sorédios com aspecto isidióide, localizados principalmente na porção basal, com muitos grânulos e esquâmulas isidióides a lobuladas, esquâmulas presentes principalmente na metade inferior, até $0,8 \mathrm{~mm}$ de comprimento; córtex 10-20 $\mu \mathrm{m}$ de espessura, medula 40-110 $\mu \mathrm{m}$ de espessura, estereoma hialino a amarelado, raramente exposto, 110-160 $\mu \mathrm{m}$ de espessura, canal central ranhurado e papilado, 400-670 $\mu \mathrm{m}$ de espessura; discos himeniais ausentes; picnídios frequentes, marginais nas cifas, amarronzados, imaturos.

Química: Testes de coloração: K-, C-, KC-, UV-. CCD: Ácido fumarprotocetrárico e uma substância não identificada com Rf C aproximado de 78 .

Cladonia subradiata é caracterizada pelo podécio geralmente simples, estreitamente cifoso, corticado somente na base, coberto por grânulos e microesquâmulas isidióides, às vezes com esquâmulas próximas a base e por produzir ácido fumarprotocetrárico (Fleig et al. 1995, Ahti 2000).

Cladonia coniocraea (Flörke) Spreng. é similar a C. subradiata por apresentar o podécio corticado somente na base, sorediado e por produzir ácido fumarprotocetrárico (Ahti \& Hammer 2002). Contudo, de acordo com Burgaz \& Ahti (2009), C. coniocraea apresenta as esquâmulas primárias profundamente laciniadas e sorediadas ao longo da margem inferior, além de apresentar sorédios farinosos no podécio, enquanto que Fleig et al. (1995) mencionaram que C. subradiata apresenta as esquâmulas primárias lobadas e sem sorédios, além de apresentar grânulos e microesquâmulas isidióides no podécio.

Assim como mencionado por Fleig et al. (1995), quando Cladonia subradiata não possui disco himenial pode ser confundida com C. macilenta por apresentar o podécio geralmente simples, ecorticado e sorediado. Contudo, C. subradiata possui o ápice do podécio estreitamente cifoso e produz ácido fumarprotocetrárico (Ahti \& Hammer 2002), enquanto que $C$. macilenta apresenta o ápice do podécio subulado a agudo, nunca cifoso, e pode produzir ácido tamnólico e/ou ácido barbático como compostos principais (Ahti 2000).

Cladonia subradiata também é bastante similar a C. polyscypha por apresentar podécio ecorticado, sorediado e por produzir ácido fumarprotocetrárico (ver comentários em Cladonia polyscypha).

Distribuição: Espécie principalmente tropical (Ahti 2000), sendo conhecida para a Ásia, Europa, África,
América do Norte e América Central (Swinscow \& Krog 1988, Aptroot 1989, Sipman \& Wolf 1998, Guo 1999, Ahti 2000). Na América do Sul, na Argentina, Bolívia, Chile, Colômbia, Equador, Guiana, Guiana Francesa, Paraguai, Peru, Suriname, Trinidad e Tobago e Venezuela (Ahti \& Kashiwadani 1984, Ferraro \& Ahti 1987, Sipman \& Aptroot 1992, Ahti 2000). É citada para os Estados do AC, AM, BA, DF, ES, MG, MS, MT, PA, PB, PE, PR, RJ, RO, RR, RS, SC, SE e SP (Osorio 1989 Osorio \& Fleig 1990, Ahti et al. 1993, Ahti 2000).

Habitat: Cladonia subradiata ocorre desde o nível do mar até 4.200 metros de altitude (Ahti 2000). Na área de estudo foi frequentemente encontrada, geralmente colonizando locais bem iluminados e frequentemente entre podécios de diversas outras espécies, tais como: Cladonia ceratophylla, C. crispatula, C. didyma, C. furfuracea, C. subsquamosa, C. ramulosa e C. ochracea. Ocorre geralmente sobre solo arenoso ou serapilheira, alguns exemplares também foram coletados sobre mourões de madeira ou sobre rocha em costões. Contudo, de acordo com Fleig et al. (1995), no Rio Grande do Sul Cladonia subradiata ocorre preferencialmente sobre lenho em decomposição, fato raramente observado na área de estudo.

Espécimes selecionados examinados: BRASIL. PARANÁ: Guaraqueçaba, Reserva Natural do Itaqui, restinga, 6-XI-2003, C.G. Donha 1502 (UPCB); Paranaguá, Parque Estadual da Ilha do Mel, restinga, $25^{\circ} 31^{\prime} \mathrm{S}, 48^{\circ} 18^{\prime} \mathrm{O}, 27-\mathrm{VIII}-2009$, E. Gumboski \& S. Eliasaro 1544, 1545 (UPCB); Pontal do Paraná, Pontal do Sul, restinga, $25^{\circ} 34^{\prime} \mathrm{S}, 48^{\circ} 21^{\prime} \mathrm{O}$, 18-II-2009, S. Eliasaro 3124 (UPCB); Matinhos, Ilha das Tartarugas, costão rochoso, $25^{\circ} 51^{\prime} \mathrm{S}, 48^{\circ} 32^{\prime} \mathrm{O}$, 21-III-2010, E. Gumboski \& F. Beilke 1829 (UPCB); Guaratuba, restinga, 8-IX-1994, E.A. Schwartz s.n. (UPCB 35494). SAnta CATARINA: São Francisco do Sul, Morro da Enseada, costão rochoso, $26^{\circ} 13^{\prime} \mathrm{S}$, 48 29'O, 5-V-2008, E. Gumboski 233 (UPCB), Parque Estadual do Acaraí, restinga, $26^{\circ} 15^{\prime} \mathrm{S}, 48^{\circ} 31^{\prime} \mathrm{O}$, 17-III-2009, E. Gumboski 697, 698, 840 (UPCB); Bombinhas, Praia de Mariscal, costão rochoso ao norte da praia, 26 ${ }^{\circ} 13^{\prime} \mathrm{S}, 48^{\circ} 29^{\prime} \mathrm{O}, 19-$ II-2010, E. Gumboski \& F. Beilke 1720 (UPCB); Imbituba, Praia de Itapirubá, costão rochoso, $28^{\circ} 20^{\prime} \mathrm{S}, 48^{\circ} 42^{\prime} \mathrm{O}, 19-\mathrm{II}-2010$, E. Gumboski \& F. Beilke 1763 (UPCB); Laguna, área ao lado da rodovia BR-101, restinga, $28^{\circ} 24^{\prime} \mathrm{S}, 48^{\circ} 47^{\prime} \mathrm{O}$, 9-III-2009, E. Gumboski 747, 787 (UPCB). 
Cladonia subsquamosa Kremp., Vidensk. Meddel. Dansk Naturhist. Foren. Kjøbenhavn 5: 366. 1873. Tipo: BRASIL. Rio DE JANEIRO: Serra d'Estrella \& Petrópolis, Warming 233 (lectótipo C, designado por Ahti (1993); Isolectótipos G, M, TUR-V 19478, UPS).

Figura 14

Talo primário: persistente a evanescente, inconspícuo, composto por esquâmulas, 0,5-1,2 $\mathrm{mm}$ de comprimento, 0,4-0,8 mm de largura, lobadas, pouco recortadas, sem sorédios, margens crenadas a lisas, sem rizinas; superfície superior lisa, pouco lustrosa a lustrosa, esverdeada, sem pruína; superfície inferior frouxamente aracnoide, branca; córtex 10-22 $\mu \mathrm{m}$ de espessura, medula 30-60 $\mu \mathrm{m}$ de espessura; picnídios ausentes. Talo secundário: $0,7-2,2 \mathrm{~cm}$ de altura, 0,5-1,2 $\mathrm{mm}$ de espessura, acinzentado a esverdeado, regularmente cifoso, às vezes com até cinco ramificações cifosas originadas da margem das cifas, capitadas quando férteis, raramente originadas do centro da cifa, cifas com 0,4-4,5 mm de diâmetro, margens suave a marcadamente denteadas, cifas totalmente sorediadas, às vezes com a superfície interna da cifa livre de sorédios deixando o estereoma exposto, sem grânulos, base não melanótica, perfurações ausentes; superfície ecorticada, levemente velosa e suavemente ranhurada, sorediada ao longo do talo, grânulos mais comuns em talos férteis, esquâmulas laciniadas, recortadas ou não, até $1,0 \mathrm{~mm}$ de comprimento, geralmente localizadas na porção basal; medula 10-40 $\mu \mathrm{m}$ de espessura, estereoma hialino a ocre, 200-265 $\mu \mathrm{m}$ de espessura, canal central levemente ranhurado e suavemente papilado, $350-900 \mu \mathrm{m}$ de diâmetro; discos himeniais frequentes, no ápice de curtos ramos originados da margem das cifas, com máximo de dez projeções na mesma cifa, até $3,0 \mathrm{~mm}$ de altura, ocre a marrom, até $1,5 \mathrm{~mm}$ de diâmetro, raramente férteis, ascósporos fusiformes, 9-13 $\times 2-4 \mu \mathrm{m}$; picnídios comuns, marginais nas cifas, negros, piriformes, conídios levemente curvados, $6-8 \times 1 \mu \mathrm{m}$.

Química: Testes de coloração: K-, C-, KC-, UV-. CCD: Ácido fumarprotocetrárico e uma substância não identificada com Rf C aproximado de 78 .

Cladonia subsquamosa é caracterizada pelo podécio regularmente cifoso, ecorticado, sorediado, às vezes com grânulos e esquâmulas (Vainio 1887) e pela produção de ácido fumarprotocetrárico (Fleig et al. 1995, Ahti 2000).
Ahti (2000)mencionou que Cladonia subsquamosa é morfológica e quimicamente muito similar a C. fimbriata (L.) Fr.. Ambas apresentam podécios constantemente cifosos, ecorticados, sorediados (Vainio 1887) e produzem ácido fumarprotocetrárico como composto principal (Burgaz \& Ahti 2009). No entanto, de acordo com Ahti (2000), C. subsquamosa possui sorédios principalmente granulares, esverdeados, caducos, deixando frequentemente a medula e estereoma expostos, principalmente na porção superior e internamente na cifa, enquanto que C. fimbriata possui sorédios farinosos, esbranquiçados e que se mantém muito mais aderidos, praticamente não deixando medula e estereoma expostos.

Cladonia chlorophaea (Flörke ex Sommerf.) Spreng. também é bastante similar a $C$. subsquamosa por possuir podécios constantemente cifosos, grânulos soredióides e ser em parte ecorticada (Swinscow \& Krog 1988). Porém, enquanto $C$. chlorophaea não apresenta sorédios verdadeiros, mas sim grânulos de tamanhos reduzidos, e a porção basal do podécio quase que continuamente corticada (Burgaz \& Ahti 2009), C. subsquamosa apresenta sorédios e é totalmente ecorticada (Ahti 2000).

Distribuição: Cosmopolita, sendo conhecida para a Oceania, Ásia, Europa, África, América do Norte e América Central (Crombie 1883, Vainio 1887, Swinscow \& Krog 1988, Fink 1919, Guo 1999, Ahti 2000). Na América do Sul, na Argentina, Bolívia, Chile, Colômbia, Equador, Guiana, Paraguai, Peru, Uruguai e Venezuela (Crombie 1876, Vainio 1903, Sipman \& Aptroot 1992, Ahti 2000). No Brasil é citada para os Estados da BA, ES, GO, MG, PB, PE, PR, RJ, RS, SC, SE e SP (Osorio \& Fleig 1989, Marcelli 1990, Ahti et al. 1993, Ahti 2000).

Habitat: Ocorre desde o nível do mar até 4.100 metros de altitude (Ahti 2000). Na área de estudo Cladonia subsquamosa é possivelmente a mais comum, sendo abundante em restingas e comum em costões rochosos. Foi encontrada colonizando diversos substratos, tais como solo arenoso, serapilheira, lenho, base e troncos de árvores vivas, troncos em decomposição, mourões de madeira, palha e sobre fina camada de sedimentos sobre rocha. Comumente ocorre com diversas outras espécies como C. subradiata, C. didyma, C. crispatula, C. confusa, C. ramulosa, C. ochracea, C. ceratophylla e C. latiloba.

Espécimes selecionados examinados: BRASIL. PARANÁ: Guaraqueçaba, Ilha das Peças, restinga, 

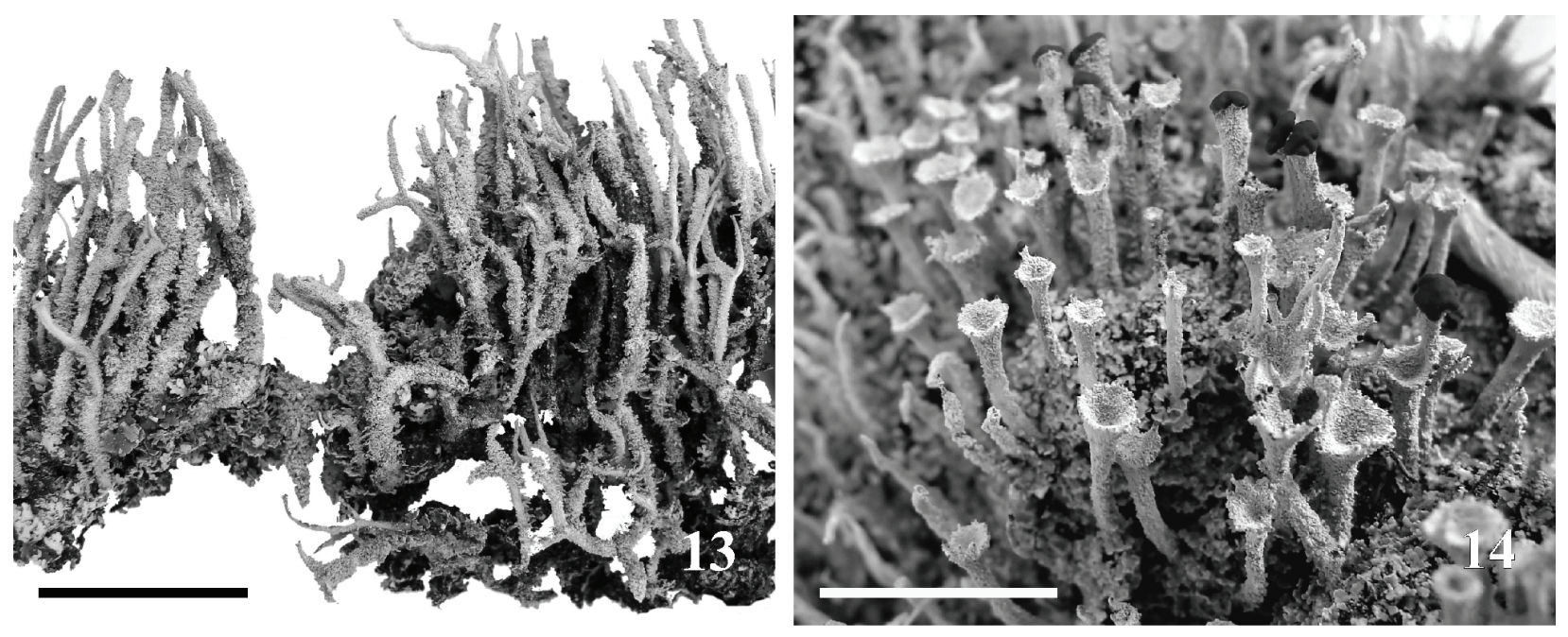

Figuras 13-14: 13. Cladonia subradiata (E. Gumboski \& F. Beilke 1829). 14. C. subsquamosa (E. Gumboski \& F. Beilke 1822). Barras de escala $=1 \mathrm{~cm}$.

Figures 13-14: 13. Cladonia subradiata (E. Gumboski \& F. Beilke 1829). 14. C. subsquamosa (E. Gumboski \& F. Beilke 1822). Scale bars $=1 \mathrm{~cm}$.

$25^{\circ} 28^{\prime} \mathrm{S}, 48^{\circ} 17^{\prime} \mathrm{O}, 20-\mathrm{III}-2010$, E. Gumboski \& F. Beilke 1807, 1822 (UPCB); Paranaguá, Parque Estadual da Ilha do $\mathrm{Mel}$, restinga, $25^{\circ} 31^{\prime} \mathrm{S}, 48^{\circ} 18^{\prime} \mathrm{O}$, 27-VIII-2009, E. Gumboski \& S. Eliasaro 1556, 1564 (UPCB); Pontal do Paraná, Pontal do Sul, restinga, 3-IV-2007, A. Yánez 1165 (UPCB), 5-IX-2007, M. Dal-Forno 237, 242 (UPCB); Matinhos, Ilha das Tartarugas, costão rochoso, $25^{\circ} 51^{\prime} \mathrm{S}, 48^{\circ} 32^{\prime} \mathrm{O}$, 21-III-2010, E. Gumboski \& F. Beilke 1840 (UPCB); Guaratuba, restinga, 8-IX-1994, E.A. Schwartz s.n. (UPCB 35495). Santa CATARINA: São Francisco do Sul, Morro da Enseada, costão rochoso, 4-IX-2009, $26^{\circ} 13^{\prime} \mathrm{S}, 4^{\circ} 29^{\prime} \mathrm{O}$, E. Gumboski 219, 390 (UPCB), Parque Estadual do Acaraí, restinga, $26^{\circ} 23^{\prime} \mathrm{S}, 48^{\circ} 33^{\prime} \mathrm{O}$, 18-IV-2009, E. Gumboski 1313, 1320, 1331 (UPCB); Bombinhas, Praia de Mariscal, costão rochoso ao norte da praia, $26^{\circ} 13^{\prime} \mathrm{S}, 48^{\circ} 29^{\prime} \mathrm{O}, 19-\mathrm{II}-2010$, E. Gumboski \& F. Beilke 1731 (UPCB); Laguna, Praia da Galheta, costão rochoso, $28^{\circ} 33^{\prime} \mathrm{S}, 48^{\circ} 47^{\prime} \mathrm{O}, 19-\mathrm{II}-2010$, E. Gumboski \& F. Beilke 1777, 1781 (UPCB).

\section{Agradecimentos}

Os autores agradecem profundamente a Dra. Ana Rosa Burgaz, Dra. Luciana da Silva Canêz, Dr. Adriano Afonso Spielmann, Dr. Marcelo Pinto Marcelli, Dr. Michel Navarro Benatti e Dr. Sammuel Hammer pelo envio de bibliografias importantes. À Dra. Soili Stenroos e ao Dr. Teuvo Ahti pelas bibliografias enviadas e discussões sobre algumas espécies. Aos curadores dos herbários ICN (Dra. Mara Rejane Ritter) e SP (Dr. Michel Navarro Benatti) pelo empréstimo dos espécimes solicitados. Aos biólogos Alice da Cruz Lima Gerlach, Flávio Beilke e Leandro Francisco de Oliveira pelo auxilio em coletas. Aos órgãos ambientais estaduais FATMA (Fundação do Meio Ambiente) e IAP (Instituto Ambiental do Paraná) pelas licenças de coletas concedidas. À CAPES (Coordenadoria de Aperfeiçoamento do Pessoal do Ensino Superior) pela concessão de bolsa de Mestrado ao primeiro autor.

\section{Literatura citada}

Ahti, T. 1976. The lichen genus Cladonia in Mongolia. Journal of Japanese Botany 51: 365-373.

Ahti, T. 1993. Names in current use in the Cladoniaceae (lichen-forming Ascomycetes) in the ranks of genus to variety. In: W. Greuter (ed.). NCU-2. Names in Current Use in the Families Trichocomaceae, Cladoniaceae, Pinaceae, and Lemnaceae. Regnum Vegetabile, Koeltz Scientific Books, Königstein, Germany, pp. 58-106.

Ahti, T. 2000. Cladoniaceae. Flora Neotropica 78. Organization for Flora Neotropica and New York Botanical Garden, New York.

Ahti, T. \& Hammer, S. 2002. Cladonia. In: T.H. Nash, B.D. Ryan, C. Gries \& F. Bungartz (eds.). Lichen Flora of the Greater Sonoran Desert Region. I. Lichens Unlimited, Arizona State University, Tempe, pp. 131-158. 
Ahti, T. \& Kashiwadani, H. 1984. The lichen genera Cladia, Cladina and Cladonia in southern Chile. In: H. Inoue (ed.): Studies on Cryptogams in Southern Chile. Kenseisha Ltd., Tokyo, pp. 125-151.

Ahti, T. \& Marcelli, M.P. 1995. Taxonomy of the Cladonia verticillaris complex in South America. In: E.E. Farkas, R. Lücking \& V. Wirth (eds.): Scripta Lichenologica - Lichenological Papers Dedicated to Antonín Vezda. Bibliotheca Lichenologica, J. Cramer, Berlin, Stuttgart, pp. 5-26.

Ahti, T., Stenroos, S. \& Xavier Filho, L. 1993. The lichen family Cladoniaceae in Paraiba, Pernambuco and Sergipe, Northeast Brazil. Tropical Bryology 7: 55-70.

Aptroot, A. 1989. Contribution to the Azores lichen flora. Lichenologist 2: 59-65.

Archer, A.W. 1992. Cladoniaceae. Flora of Australia 54: 107-152.

Asahina, Y. 1940. Chemismus der Cladonien unter besonderer Berücksichtigung der Japanischen Arten I. Cladonia chlorophaea und verwandte Arten. Journal of Japanese Botany 16: 709-727.

Brodo, I.M., Sharnoff, S.D. \& Sharnoff, S. 2001. Lichens of North America, New Haven andYale University Press, London.

Burgaz, A.R. \& Ahti, T. 2009. Cladoniaceae. Flora Liquenológica Ibérica. Volume 4. Sociedad Española de Liquenología (SEL), Madrid.

Calvelo, S. \& Liberatore, S. 2002. Catálogo de los líquenes de la Argentina. Kurtziana 29: 7-170.

Crombie, J.M. 1876. On the Lichens collected by Prof. R.O. Cunningham in the Falkland Islands, Fuegia, Patagonia and the Island of Chiloe during the voyage of H.M.S. Nassau 1867-1869. Botanical Journal of the Linnean Society 15: 222.

Crombie, J.M. 1883. Enumeration of the British Cladoniei. Grevillea 11: 111-115.

Culberson, C.F. \& Ammann, K. 1979. Standard method zur Dünnschichtchomatographie von Flechtensubstanzen. Herzogia 5: 1-24.

Elix, J.A. \& Ernst-Russell, K.D. 1993. A Catalogue of Standardized Thin Layer Chromatographic Data and Biosynthetic Relationships for Lichen Substances. 2nd ed. Australian National University Camberra, Camberra.

Ferraro, L.I. \& Ahti, T. 1987. Contribucion al conocimiento del genero Cladonia (Cladoniaceae-Liquenes) de Argentina y regiones limitrofes. Bonplandia 6: 57-69.

Fink, B. 1919. Additions to lichen distribution in North America. Mycologia 11: 296-307.

Flakus, A., Ahti, T., Kukwa, M., Wilk, K. 2008. New and interesting records of Cladonia and their lichenicolous fungi from the Andean cloud forest in Bolivia. Annales Botanici Fennici 45: 448-454.

Fleig, M., Ahti, T. \& Stenroos, S. 1995. A família Cladoniaceae (liquens) no Rio Grande do Sul, Brasil. Napaea 11: 1-29.
Galloway, D.J. 1985. Flora of New Zealand Lichens. P.D. Hasselberg, Government Printer, Wellington. 1XXIII.

Grassi, M.M. 1950. Contribución al catalogo de liquenes argentinos, I. Lilloa 24: 5-296.

Gumboski, E.L. 2011. Cladonia (Cladoniaceae, Ascomycota Liquenizados) em ambientes de restingas e costões rochosos no Paraná e Santa Catarina. Dissertação de Mestrado. Universidade Federal do Paraná, Curitiba.

Gumboski, E.L. \& Eliasaro, S. 2011a. Cladonia litoralis (Cladoniaceae), a new species from southern Brazil. The Bryologist 114: 665-667.

Gumboski, E.L. \& Eliasaro, S. 2011b. Checklist of lichenized fungi of Santa Catarina State (Brazil). Mycotaxon 115: 535.

Guo, S.Y. 1999. Fungal flora of tropical Guangxi, China: the lichen family Cladoniaceae. Mycotaxon 72: 339-347.

Krempelhuber, A. 1876. Lichenes brasilienses collecti a D.A. Glaziou in provincia brasiliensi Rio Janeiro. Flora 59: 56-63.

Laundon, J.R. 1984. The typification of Withering's neglected lichens. Lichenologist 16: 211-239.

Marcelli, M.P. 1990. Líquens das Restingas e Manguezais da Ilha do Cardoso. I. In: II Simpósio de Ecossistemas da Costa Sul e Sudeste Brasileira: Estrutura, Função e Manejo. Águas de Lindóia, Estado de São Paulo, pp. 382-392.

Marcelli, M.P. 1992. Ecologia Liquênica nos Manguezais do Sul-Sudeste Brasileiro. Bibliotheca Lichenologica 47: 1-288.

Müller [Argoviensis], J. 1881. Lichenologische Beiträge. Flora 64: 81-88.

Müller [Argoviensis], J. 1891a. Lichenes Catharinenses a cl. E. Ule in Brasilia prov. Santa Catharina lecti. Hedwigia 30: 235-243.

Müller [Argoviensis], J. 1891b. Lichenes Schenckiane a cl. Dr. H. Schenck, Bonnensi, in Brasiliae orientalis prov. Santa Catharina, Paraná, Rio de Janeiro, Minas Geraes et Pernambuco lecti. Hedwigia 30: 219-234.

Osorio, H.S. 1989. Contribution to the lichen flora of Brazil. XXIII. Lichens from São Paulo City. Mycotaxon 36: 161-162.

Osorio, H.S. \& Fleig, M. 1988a. Contribution to the lichen flora of Brazil. XX. Additional records from São Francisco de Paula, Rio Grande do Sul State. Comunicaciones Botanicas del Museo de Historia Natural de Montevideo 5: 1-7.

Osorio, H.S. \& Fleig, M. 1988b. Contribution to the lichen flora of Brazil. XXI. Lichens from Morro Santana, Rio Grande do Sul State. Comunicaciones Botanicas del Museo de Historia Natural de Montevideo 5: 1-3.

Osorio, H.S. \& Fleig, M. 1989. Contribution to the lichen flora of Brazil. XXV. Lichens from Parque Nautico, Santa Maria, Rio Grande do Sul State. Comunicaciones Botanicas del Museo de Historia Natural de Montevideo 5: 1-4. 
Osorio, H.S. \& Fleig, M. 1990. Contribution to the lichen flora of Brazil. XXVI. Lichens from Vale do Diabo, Rio Grande do Sul State. Comunicaciones Botanicas del Museo de Historia Natural de Montevideo 5: 1-6.

Osorio, H.S. \& Fleig, M. 1991. Contribution to the lichen flora of Brazil. XXVIII. Lichens from northern Santa Maria, Rio Grande do Sul State. Comunicaciones Botanicas del Museo de Historia Natural de Montevideo 5: $1-7$.

Santesson, R. 1942. The South American Cladinae. Arkiv för Botanik 30A: 1-27.

Sipman, H.J.M. 1990. Lichenotheca Latinoamericana a museo botanico berolinensi edita, fasciculum primum. Willdenowia 19: 543-551.

Sipman, H.J.M \& Wolf, J.H.D. 1998. Provisional checklist for the lichens of Chiapas. Acta Botánica Mexicana 45: 1-29.

Sipman, H.J.M. \& Aptroot, A. 1992. Results of a botanical expedition to Mount Roraima, Guyana. II. Lichens. Tropical Bryology 5: 79-108.

Stenroos, S., Hyvönen, J., Myllys, L., Thell, A. \& Ahti, T. 2002a. Phylogeny of the Genus Cladonia s.lat. (Cladoniaceae, Ascomycetes) Inferred from Molecular, Morphological, and Chemical Data. Cladistics 18: 237-278.
Stenroos, S., Myllys, L., Thell, A. \& Hyvönen, J. 2002b. Phylogenetic hypotheses: Cladoniaceae, Stereocaulaceae, Baeomycetaceae, and Icmadophilaceae revisited. Mycological Progress 1: 267-282.

Swinscow, T.D.V.\& Krog, H. 1988. Macrolichens of East Africa. British Museum (Natural History), London.

Taylor, C.J. 1967. The lichens of Ohio. Part I. Foliose lichens. The Ohio Biological Survey, The Ohio State University Press, Columbia.

Taylor, C.J. 1968. The lichens of Ohio. Part II. Fruticose lichens. The Ohio Biological Survey, The Ohio State University Press, Columbia.

Thomson, J.W. 1967. The Lichen Genus Cladonia in North America. University of Toronto Press, Toronto.

Vainio, E.A. 1887. Monographia Cladoniarum universalis. I. Acta Dept. Bot., Univ. Helsinki 13, 1-15. Acta Societatis Pro Flora Et Fauna Fennica 4: 1-509.

Vainio, E.A. 1894. Monographia Cladoniarum universalis. II. Acta Societatis Pro Flora Et Fauna Fennica 10: 1-498.

Vainio, E.A. 1903. Lichens. In: Expédition antarctique Belge. Résultats du voyage du S.Y. Belgica en 18971898-1899 sous commandement de A. de Gerlache de Gomery, rapports scientifiques. J.E. Buschmann, Anvers. 
